\title{
A constitutive model for partially saturated soils
}

\author{
E. E. ALONSO*, A. GENS* and A. JOSA*
}

The Paper presents a constitutive model for describing the stress-strain behaviour of partially saturated soils. The model is formulated within the framework of hardening plasticity using two independent sets of stress variables: the excess of total stress over ajr pressure and the suction. The model is able to represent, in a consistent and unified manner, many of the fundamental features of the behaviour of partially saturated soils which had been treated separately by previously proposed models. On reaching saturation, the model becomes a conventional critical state model. Because experimental evidence is still limited, the model has been kept as simple as possible in order to provide a busic framework from which extensions are possible. The model is intended for partially saturated soils which are slightly or moderately expansive. After formulating the model for isotropic and triaxial stress states, typical predictions are described and compared, in a qualitative way, with characteristic trends of the behaviour of partially saturated soils. Afterwards, the results of a number of suction-controlled laboratory tests on compacted kaolin and a sandy clay are used to evaluate the ability of the model to reproduce, quantitatively, observed behaviour. The agreement between observed and computed results is considered satisfactory and confirms the possibilities of reproducing the most important features of partially saturated soil behaviour using a simple general framework.

KEYWORDS: compaction; constitutive relations; partial saturation; plasticity.
L'article présente un modèle constitutif pour décrire le comportement contrainte/déformation des sols partiellement saturés. Le modèle est formulé dans le cadre de la plasticité qui s'endurcit, en utilisant deux jeux indépendants de variables de contrainte, c'est-à-dire l'excès de la contrainte totale sur la pression de l'air et la succion. Le modèle peut représenter d'une façon logique et unifiée beaucoup des caractéristiques fondamentales du comportement des sols partiellement saturés qui avaient été traités séparément dans des modèles proposés précédemment. Lorsque la saturation est atteinte le modèle devient un modèle conventionnel d'état critique. Comme les données expérimentales restent encore limitées, le modèle d'été simplifié le plus que possible, afin de fournir un cadre de base à partir duquel des extensions sont possibles. Le modèle convient à des sols particllement saturés qui sont expansifs à un degré faible ou modéré. Le modèle est d'abord formulé pour des états de contrainte isotropes et triaxiaux. Puis l'article décrit des prédictions typiques et les compare de façon qualitative avec des tendances caractéristiques du comportement des sols partiellement saturés. Les résultats de quelques essais régis par la succion effectués dans le laboratoire sur du kaolin compact et sur une argile sablonneuse sont utilisés afin d'évaluer la capacité du modèle de reproduire de façon quantitative le comportement observé. On considère que les résultats observés et calculés s'accordent bien et qu'ils confirment les possibilités de reproduire les caractéristiques les plus importantes du comportement des sols partiellement saturés par l'utilisation d'un cadre général très simple.

\section{NOTATION \\ $a, b, c, d$ parameters of the state surface for specific volume \\ $e$ void ratio \\ $G$ shear modulus \\ $K_{0} \quad$ lateral stress coefficient \\ $k$ parameter describing the increase in cohesion with suction}

\footnotetext{
Discussion on this Paper closes 4 January 1991; for further details see $p$. ii.

* Civil Engineering School, Technical University of Catalunya, Barcelona, Spain.
}

$M \quad$ slope of critical state lines

$N(s)$ specific volume at $p=p^{\mathrm{c}}$

$m, n$ parameters of the state surface for degree of saturation

$p$ excess of mean stress over air pressure (net mean stress)

$p_{\text {at }}$ atmospheric pressure

$p_{0}$ preconsolidation stress

$p_{0}{ }^{*}$ preconsolidation stress for saturated conditions

$p^{c} \quad$ reference stress

$q$ deviatoric stress $\left(=\sigma_{1}-\sigma_{3}\right)$

$r$ parameter defining the maximum soil stiffness 
$S_{\mathrm{r}}$ degree of saturation

$s$ suction $\left(=u_{\mathrm{a}}-u_{\mathrm{w}}\right)$

$s_{0}$ hardening parameter of the suction increase yield curve

$u_{\mathrm{a}}$ air pressure

$u_{\mathrm{w}}$ water pressure

$v$ specific volume

$\beta$ parameter controlling the rate of increase of soil stiffness with suction

$\varepsilon_{1}, \varepsilon_{3}$ principal strains

$\varepsilon_{1}{ }^{e}, \varepsilon_{3}{ }^{e}$ elastic principal strains

$\varepsilon_{1}{ }^{p}, \varepsilon_{3}{ }^{p} \quad$ plastic principal strains

$\varepsilon_{\mathrm{s}}, \varepsilon_{\mathrm{s}}{ }^{e}, \varepsilon_{\mathrm{s}}^{\mathrm{p}}$ total, elastic and plastic deviatoric strains

$\varepsilon_{\mathrm{v}}, \varepsilon_{\mathrm{v}}{ }^{\mathrm{e}}, \varepsilon_{\mathrm{v}}{ }^{\mathrm{p}}$ total, elastic and plastic volumetric strains

$\varepsilon_{\mathrm{vp}}{ }^{e} \quad$ elastic volumetric strain induced by changes in net mean stress

$\varepsilon_{\mathrm{vp}}{ }^{\mathrm{p}}$ plastic volumetric strain associated with the LC yield surface

$\varepsilon_{\mathrm{vp}} \quad\left(\varepsilon_{\mathrm{vp}}{ }^{\mathrm{e}}+\varepsilon_{\mathrm{vp}}^{\mathrm{p}}\right)$

$\varepsilon_{\mathrm{vs}} \mathrm{e}^{\mathrm{e}}$ elastic volumetric strain induced by changes in suction

$\varepsilon_{v s}^{p}$ plastic volumetric strain associated with the SI yield surface

$\varepsilon_{\mathrm{vs}} \quad\left(\varepsilon_{\mathrm{vs}}{ }^{\mathrm{e}}+\varepsilon_{\mathrm{vs}}{ }^{\mathrm{p}}\right)$

$\varphi^{\prime}$ saturated friction angle

$\kappa$ elastic stiffness parameter for changes in net mean stress

$\kappa_{\mathrm{s}} \quad$ elastic stiffness parameter for changes in suction

$\lambda(s) \quad$ stiffness parameter for changes in net mean stress for virgin states of the soil

$\lambda_{\mathrm{s}}$ stiffness parameter for changes in suction for virgin states of the soil

$\sigma_{1}, \sigma_{2}, \sigma_{3}$ total principal stresses

$\sigma_{i j}$ total stresses

$\sigma_{\mathrm{m}}$ total mean stress $\left(=\left(\sigma_{1}+\sigma_{2}+\sigma_{3}\right) / 3\right)$

\section{INTRODUCTION}

The description of the stress-strain behaviour of partially saturated soils has been closely linked with efforts to isolate the relevant stress variables concerning soil behaviour. Difficulties in finding a single effective stress equation, illustrated in the works of Aitchison and Donald (1956), Bishop and Donald (1961), Bishop and Blight (1963) and Burland (1965), progressively led to the acceptance of two effective stress fields as a necessary framework to describe the observed features of partially saturated soil behaviour under paths involving the variation of total stress and pore water pressure deficiency (or suction).

Important contributions to this topic were the early works of Bishop \& Donald (1961), Coleman (1962), Matyas \& Radhakrishna (1968) and the null tests reported by Fredlund \& Morgenstern (1977) which led to a formal proposition of any pair of stress fields among the following three stress states: $\left(\sigma_{\mathrm{ij}}-u_{\mathrm{a}} \delta_{\mathrm{ij}}\right) ;\left(\sigma_{\mathrm{ij}}-u_{\mathrm{w}} \delta_{\mathrm{ij}}\right)$ and $\left(u_{\mathrm{a}}\right.$ $\left.-u_{\mathrm{w}}\right) \delta_{\mathrm{ij}}$ as a suitable stress framework to describe stress-strain-strength behaviour of partially saturated soils. In these expressions, $\sigma_{\mathrm{ij}}$ is the total stress, $u_{\mathrm{a}}$ and $u_{\mathrm{w}}$ the air and water pressure and $\delta_{i j}$ the Kronecker delta. Under conditions of partial saturation the term $u_{\mathrm{a}}-u_{\mathrm{w}}$ is a positive quantity and will be denoted as the suction term $s$.

Adopting the suction and the excess of total stress over air pressure as the relevant stress variables, several aspects of the mechanical behaviour of partially saturated soils have been modelled in the past through constitutive relationships. Some of these models which cover partial aspects of the stress-strain behaviour are

(a) The incremental stress-strain relations suggested by Coleman (1962) to relate changes in $s$ and $\sigma_{\mathrm{ij}}-u_{\mathrm{a}} \delta_{\mathrm{ij}}$ to the strain response of the soil. This is essentially an incremental elastic type of formulation and it was also proposed by Fredlund (1979) who recognized the nonlinear character of the moduli involved in the incremental relations.

(b) The description of volumetric behaviour by means of state surfaces in a three-dimensional $\left[e,\left(\sigma-u_{\mathrm{a}}\right), s\right]$ space. These surfaces are able to describe the transitions from swelling to collapse behaviour when the total stress increases. They were formally introduced by Matyas \& Radhakrishna (1968). Based on experimental results, Fredlund (1979) and Lloret \& Alonso $(1980,1985)$ proposed mathematical expressions for these surfaces, for a class of imposed stress paths.

(c) An extension of the Mohr-Coulomb failure criteria to include partial saturation, through a new angle of friction relating changes in shear strength to changes in suction (Fredlund, Morgenstern \& Widger, 1978). The original linear expression has been recently questioned in view of increasing experimental evidence (Escario \& Sáez, 1986, 1987; Fredlund, Rahardjo \& Gan, 1987).

These valuable efforts are, however, unable to provide an integrated scheme for a stress-strain characterization of partially saturated soils. In addition, some basic features of partially saturated soil behaviour such as its strong stress path dependence are poorly represented by the existing models.

In devising the model, simplicity was considered a desirable feature. Nevertheless, fundamental tendencies of observed behaviour of partially saturated soils are believed to be rep- 
resented by the model. The model, which uses well established concepts of the theory of hardening plasticity and reduces to a critical state model when the soil reaches full saturation, offers room for improvement when more experimental evidence becomes available. A qualitative description of this model and its relationship with observed behaviour is given in Alonso, Gens \& Hight (1987).

The model described in this Paper is intended for partially saturated soils which are slightly or moderately expansive such as partially saturated sands, silts, clayey sands, sandy clays and clays of low plasticity. It is also thought that some features of the behaviour of expansive clays are suitably represented by the proposed model as well. However, a comprehensive description of this type of soil will probably require significant modifications of the model described below.

\section{FEATURES OF BEHAVIOUR OF PARTIALLY SATURATED SOIL}

Some patterns of the behaviour of non-plastic and moderately expansive partially saturated soils have been established in the past three decades through experimental work involving mainly oedometer testing (with or without suction control) and, to a lesser extent, triaxial and direct shear testing. The main features of this bchaviour are summarized in the following paragraphs. Additional details are given in Alonso, Gens \& Hight (1987).

Suction contributes to stiffening the soil against external loading. This is a well proved result when compacted samples either dry or wet of optimum are loaded in compression (Rico \& Del Castillo, 1976). The oedometric results of samples tested at different moisture conditions can also be interpreted as an increase in the apparent preconsolidation stress as suction increases (Dudley, 1970).

If the natural depositional processes or the compaction method induce an open structure in the soil, a reduction in suction (wetting) for a given confining stress may induce an irrecoverable volumetric compression (collapse). For a certain range of the confining stress (which varies from soil to soil) the amount of collapse increases with the intensity of the confining stress (Blight, 1965; Barden, Madedor \& Sides, 1969; Dudley, 1970; Booth, 1975; Jennings \& Knight, 1975; Erol \& El Ruwaih, 1982; Yudhbir, 1982). However, as the confining stress is increased, the amount of collapse may reach a maximum followed by decreasing values. Results compiled by Yudhbir (1982) for different residual soils show that the confining stress leading to the maximum collapse varies widely for different initial conditions. Similar qualitative results for compacted samples of a low plasticity residual clay have been reported by Booth (1975). Finally, once wetted, the collapsed sample follows, approximately, the stress-strain path of an initially saturated sample in compression (Erol \& El Ruwaih, 1982, testing a natural loess; Maswoswe, 1985, testing a sandy clay).

Any partially saturated soil included in the types mentioned (and even active clays) may either expand or collapse on wetting if the confining stress is sufficiently low (expansion) or high (collapse). Among many others, results of this type may be found in Maswoswe (1985) (testing a statically compacted sandy clay) and Justo, Delgado \& Ruiz (1984) (testing compacted samples of expansive clay).

Suction controlled experiments have revealed, however, that a reversal in volumetric behaviour may also occur during the wetting process. In fact, potentially collapsible microstructures subjected to a suction reduction from a relatively high initial value have been reported to experience first an expansion and then a compressive strain (Escario \& Sáez, 1973; Cox, 1978; Josa, Alonso, Lloret \& Gens, 1987).

The volumetric response of partially saturated soils depends not only on the initial and final stress and suction values but on the particular path followed from the initial to the final state. It has been often reported (Matyas \& Radhakrishna, 1968; Barden et al., 1969; Lloret \& Alonso, 1985; Josa et al., 1987) that paths which involve loading steps and non-increasing suction are essentially path independent. However, significant departures from this result are obtained when the stress path involves an increase in suction and an increase in external load. The state surfaces described by some of the authors listed above are only meaningful if stress-path independence is guaranteed.

Changes in suction may induce irreversible volumetric deformations. This behaviour may be investigated by subjecting samples of soil to drying-wetting cycles. Tests of this type have been reported by Yong, Japp \& How (1971) for a kaolinite and a natural low activity clay and by Josa et al. (1987) for a moderately plastic kaolin. In both cases plastic volumetric strains were measured as a consequence of a drying process.

For a limited range of confining stress and applied suction, shear strength tests reported by Fredlund et al. (1978), Gulhati and Satija (1981), Ho and Fredlund (1982) and Fredlund \& Rahardjo (1985) may be interpreted in the sense that an increase in suction results in an increase in effective cohesion while maintaining constant 
the (saturated) friction angle $\phi$. Departures from this pattern have been reported by Escario and Sáez (1986) and Delage, Suraj de Silva \& De Laure (1987). The increase in strength cannot continue indefinitely with applied suction. Some recent results reported by Escario and Sáez (1987) and Fredlund et al. (1987), which extend the suction ranges used in previously published results, indicate a non-linear increase of strength with suction and a tendency towards a maximum at some given (high) suction.

Most of this experimental evidence has been used to develop a model which could offer a unified approach to some fundamental features of the behaviour of partially saturated soils. The conceptual bases for the model and the basic formulation are given in the next sections. Examples of the response of the model to some imposed stress and strain conditions are then presented. Finally, a comparison between predicted and measured response for some suction controlled tests will be made. This comparison will also allow a more detailed presentation of some features of the behaviour of partially saturated soils which have only been outlined in the summary above.

\section{FORMULATION OF MODEL FOR ISOTROPIC STRESS STATES \\ Stress states inducing yield}

A suitable stress space to describe isotropic states is $(p, s)$ where $p=\sigma_{\mathrm{m}}-u_{\mathrm{a}}$ (net mean stress) is the excess of mean stress $\sigma_{\mathrm{m}}$ over air pressure and $s$ is the suction. The purpose of this section is to derive a yield locus in the $(p, s)$ space using as background information the behaviour of saturated soils (which impose a limiting condition to partially saturated soils) and observed features of isotropic and oedometer testing under controlled suction.

It is not strictly necessary to derive a yield function in the way described below. It may simply be proposed, on the basis of observed yield behaviour, as a mathematical relationship that involves constitutive parameters. Stress path testing may later be used to check the overall behaviour of the model and its ability to reproduce measured stress-strain response of the soil. However, it is convenient in this case to present a formal derivation of the yield function to underline 'ab initio' the relationship of yield states with observed volumetric behaviour of partially saturated soils and to incorporate the well established features of isotropic or oedometer compression of saturated soils. In this way the developed framework will be hopefully well rooted in commonly observed experimental behaviour.
Consider an isotropic test in which a soil sample at a given suction (subsequently maintained) is subjected to $p$-load increments along virgin states. In full correspondence with the behaviour of saturated soils the specific volume, $v=1+e$, will be given by

$$
v=N(s)-\lambda(s) \ln \frac{p}{p^{\mathrm{c}}}
$$

where $p^{c}$ is a reference stress state for which $v=N(s)$. On unloading and reloading (at constant s) the soil is supposed to behave elastically:

$$
\mathrm{d} v=-\kappa \frac{\mathrm{d} p}{p}
$$

In these equations the stiffness parameter $\lambda(s)$ depends on suction in accordance with observations reported in the previous section. A dependence of $N(s)$ on $s$ will be maintained for the sake of generality. Although some dependence of $\kappa$ on $s$ is also likely, a constant value has been adopted to ensure that the elastic part of the model is conservative. A schematic representation of Equations (1) and (2) is given in Fig. 1.

Consider in Fig. 2(a) the response to isotropic loading of two samples subjected to different suctions: $s=\mathbf{0}$ (saturated case) and a larger suction $s$. The saturated preconsolidation stress is labelled $p_{0}{ }^{*}$ (point 3 in Fig. 2(a)). The second sample will yield at a larger isotropic stress $p_{0}$ (point 1$)$.

If both points, 1 and 3 , belong to the same yield curve in a $(p, s)$ stress plane (Fig. 2(b)), a relationship between the generic yield stress, $p_{0}$ and the saturated value $p_{0}{ }^{*}$ can now be obtained by relating the specific volumes at points 1 and 3 through a virtual path which involves an initial unloading, at constant suction, from $p_{0}$ to $p_{0}{ }^{*}$, and a subsequent reduction in suction, from $s$ to zero, at constant stress $\left(p_{0}{ }^{*}\right)$. The sample, initially at point $1(p, s)$ follows the path 1-2-3 (Figs 2(a)

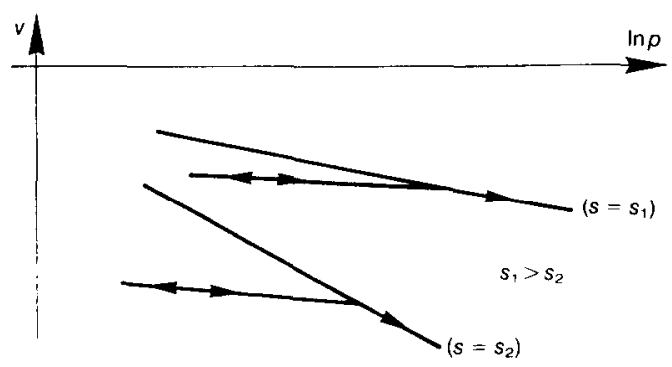

Fig. 1. Proposed variation of specific volume with net mean stress and suction along virgin and unloadingreloading paths 


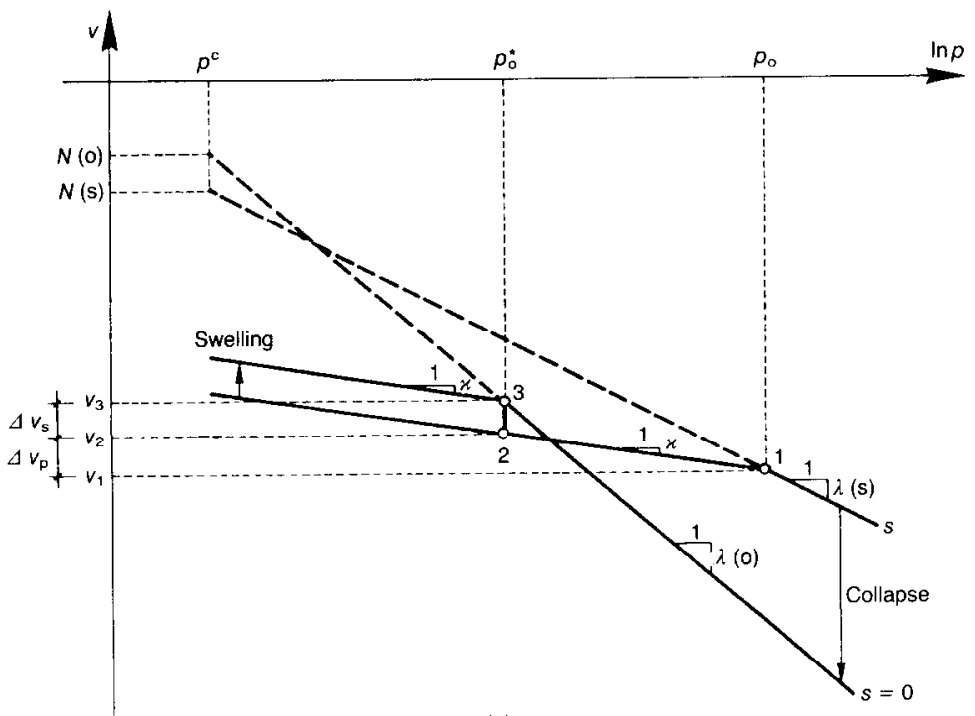

(a)

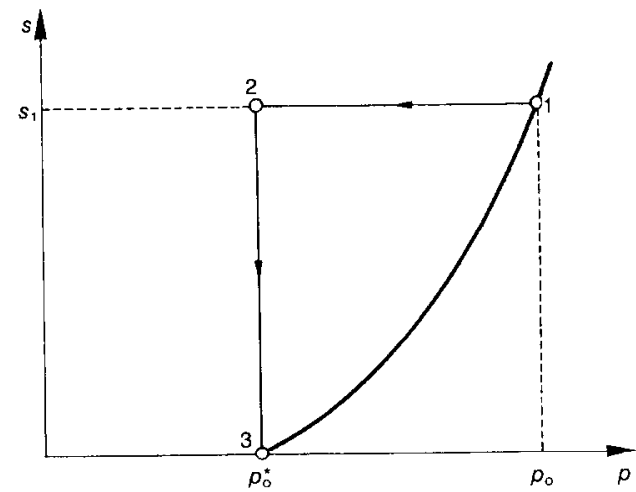

(b)

Fig. 2. Relationship between preconsolidation stresses $p_{0}$ and $p_{0}{ }^{\star}$ : (a) compression curves for saturated and unsaturated soil; (b) stress path and yield curve in $(p, s)$ stress plane

and $2(b))$. The following identity may be established

$$
v_{1}+\Delta v_{\mathrm{p}}+\Delta v_{\mathrm{s}}=v_{3}
$$

where the different quantities are indicated in Fig. 2(a).

The suction unloading (wetting) from 2 to 3 occurs in the elastic domain. Under these circumstances a reversible swelling $\Delta v_{\mathrm{s}}$ takes place which is given by a logarithmic expression similar to Equation (2)

$$
\mathrm{d} v=-\kappa_{\mathrm{s}} \frac{\mathrm{d} s}{\left(s+p_{\mathrm{at}}\right)}
$$

$p_{\text {at }}$ has been added to $s$ to avoid infinite values as $s$ approaches zero.

Taking into account Equations (1), (2) and (4), Equation (3) becomes

$$
\begin{array}{r}
N(s)-\lambda(s) \ln \frac{p_{0}}{p^{\mathrm{c}}}+\kappa \ln \frac{p_{0}}{p_{0}{ }^{*}}+\kappa_{\mathrm{s}} \ln \frac{s+p_{\mathrm{at}}}{p_{\mathrm{at}}} \\
=N(0)-\lambda(0) \ln \frac{p_{0}{ }^{*}}{p^{\mathrm{c}}}
\end{array}
$$

which provides a relationship between $p_{0}$ and $s$ as a function of some reference stress values $\left(p_{0}{ }^{*}, p^{\mathrm{c}}\right)$ and some soil parameters $\left(N(s), \lambda(s), \kappa, \kappa_{\mathrm{s}}\right)$. A convenient choice of $p^{c}$ and $N(s)$ to simplify Equation 
(5) is to assume (Fig. 2(a))

$$
\left.\Delta v\left(p^{\mathrm{c}}\right)\right|_{\mathrm{s}} ^{0}=N(0)-N(s)=\kappa_{\mathrm{s}} \ln \frac{s+p_{\mathrm{at}}}{p_{\mathrm{at}}}
$$

In other words, $p^{c}$ is the net mean stress at which one may reach the saturated virgin state, starting at a partially saturated condition, through a wetting path which involves only (elastic) swelling.

If Equation (6) is introduced into Equation (5), the following relationship is obtained

$$
\left(\frac{p_{0}}{p^{\mathfrak{c}}}\right)=\left(\frac{p_{0}^{*}}{p^{\mathfrak{c}}}\right)^{[\lambda(0)-\kappa] /[\lambda(s)-\kappa]}
$$

This Equation defines the set of yicld $p_{0}$ values for each associated suction (it can be considered therefore as a family of yield curves in a $(p, s)$ space). In order to isolate a single yield curve it is necessary to specify the preconsolidation net mean stress for saturated conditions $\left(p_{0}^{*}\right)$ which may be viewed as the hardening parameter in Equation (7). This Equation plays a central role in the model developed and explains, as discussed at length later, not only the apparent increase in preconsolidation stress associated with increasing suction, but also the collapse phenomena observed in wetting paths. For this reason, the yield curves (7) will be named LC yield curves (after loading-collapse). An LC yield curve through points 1 and 3 has been sketched in Fig. 2(b). Note that when $p_{0}{ }^{*}=p^{\mathrm{c}}$ the LC yield curve becomes a straight line $\left(p_{0}=p^{\mathrm{c}}\right)$. In this case, changes in $s$ do not result in plastic deformations. Only the elastic component, as given hy Equation (4), is maintained.

Existing information on the volumetric behaviour of partially saturated soils, as revealed by suction controlled tests, may be used to support some of the model assumptions. The results of a number of isotropic and oedometer tests of this type were compiled by Lloret \& Alonso (1985) and reported in terms of state surfaces (the void ratio was expressed as a function of net vertical or net confining stress and suction). Surface fitting analysis was performed in order to find the most appropriate analytical expression for the analysed data. The tests considered involved different soil types (low plasticity clays, silty clay and clayey sand) and suction values ranging from zero to 100 $\mathrm{kPa}$ in most of the cases.

Most of the reported state surfaces have been obtained through stress paths which involve reductions in suction from an initial value and a subsequent increment in net mean (or vertical) stress $p$. A path of this kind is shown in Fig. 3. For this particular path, the final specific volume for the (generic) stress state $(p, s)$ may be written:

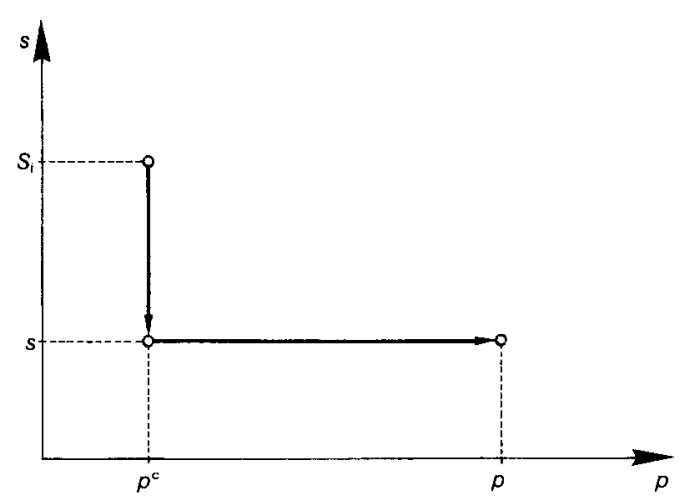

Fig. 3. Wetting and loading stress path in $(p, s)$ stress plane

$$
v(p, s)=v\left(p^{c}, s_{\mathrm{i}}\right)+\left.\Delta v\left(p^{\mathrm{c}}\right)\right|_{s_{1}} ^{s}+\lambda(s) \ln \frac{p}{p^{\mathrm{c}}}
$$

where the $p$-loading was supposed to take place along virgin states. This expression may be compared with the following empirical equation which was found by Lloret \& Alonso (1985) to fit well experimental results

$$
\begin{aligned}
v & =a+b \ln \frac{p}{p^{\mathrm{c}}}+c \ln s+d \ln \frac{p}{p^{\mathrm{c}}} \ln s \\
& =a+c \ln s+(b+\mathrm{d} \ln s) \ln \frac{p}{p^{\mathrm{c}}}
\end{aligned}
$$

where $a, b, c$ and $d$ are constants.

Identifying Equations (8) and (9) suggests that

$$
v\left(p^{\mathfrak{c}}, s_{\mathrm{i}}\right)+\left.\Delta v\left(p^{\mathfrak{c}}\right)\right|_{s_{\mathrm{i}}} ^{s}=a+c \ln s
$$

which supports the logarithmic variation of $v$ with suction adopted in Equation (6).

In addition Equation (9) provides an expression describing the increase in soil stiffness with suction:

$$
\lambda(s)=b+\mathrm{d} \ln s
$$

This expression may adequately predict an increase in soil stiffness with suction if $d<0$. It predicts, however, an unlimited increase in stiffness for increasing $s$ and this is a limitation for wide ranges of suction changes.

An asymptotic maximum stiffness, which is probably closer to real behaviour, is predicted by the alternative equation

$$
\lambda(s)=\lambda(0)[(1-r) \exp (-\beta s)+r]
$$

where $r$ is a constant related to the maximum stiffness of the soil (for an infinite suction), $r=\lambda(s \rightarrow \infty) / \lambda(0)$, and $\beta$ is a parameter which 
controls the rate of increase of soil stiffness with suction. Equation (12) has been adopted in the remainder of this Paper given its superior predicting capabilities as compared with Equation (11). Different expressions may be used for the (virgin) coefficient of compressibility when more experimental evidence becomes available. Fig. 4 illustrates the shape of the LC yield curves, when $\lambda(s)$ is given by Equation (12), for selected values of parameters $p_{0}{ }^{*}, r$ and $\beta$. Other parameters used in drawing Fig. 4 are $p^{*}=0.1 \mathrm{MPa}, \lambda(0)=0.2$ and $\kappa=0.02$.

As reviewed in a previous section, an increase in suction may also induce irrecoverable strains.
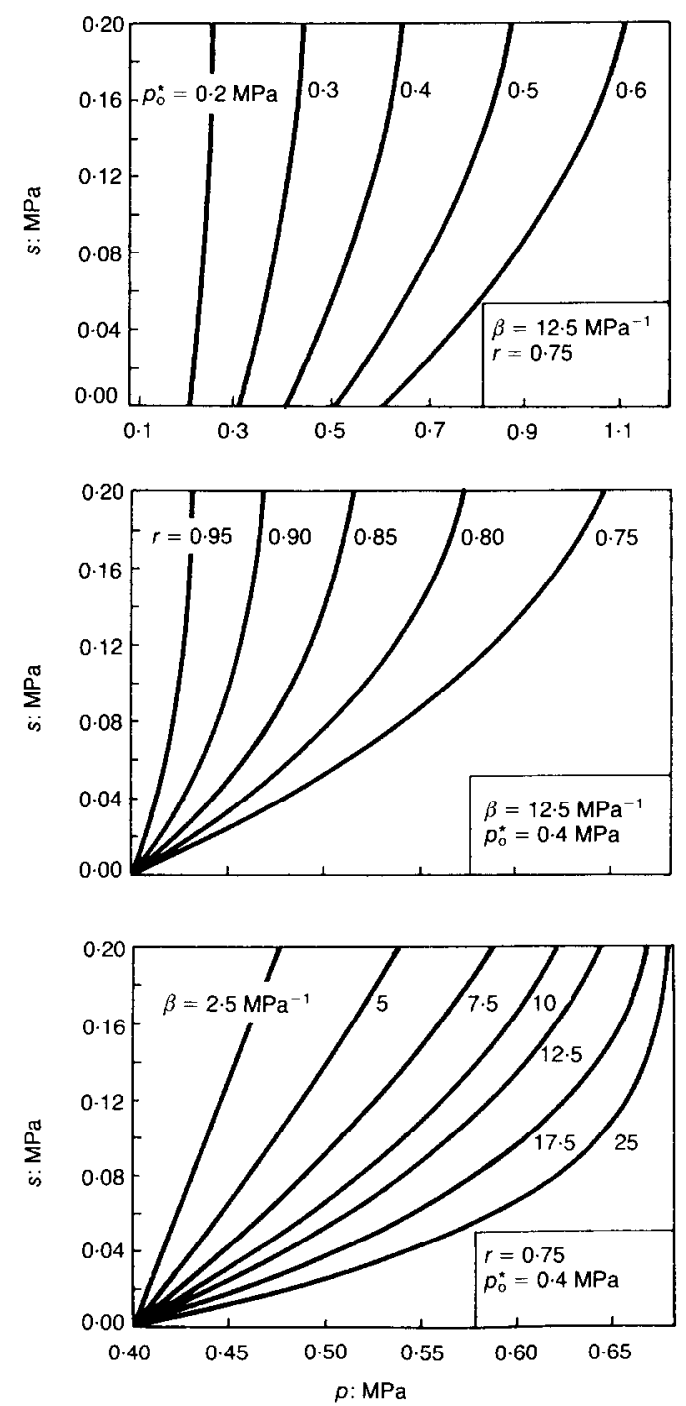

Fig. 4. Shapes of the LC yield curve far wiferent values of the parameters $p_{0}^{*}, r$ and $\beta$
It is proposed that whenever the soil reaches a maximum previously attained value of the suction $s_{0}$, irreversible strains will begin to develop. As a preliminary and simple choice, before more experimental evidence becomes available, the following yield condition

$$
s=s_{0}=\text { constant }
$$

is adopted. $s_{0}$ has the meaning of the maximum past suction ever experienced by the soil and bounds the transition from the elastic state to the virgin range when suction is increased (Fig. 5). This yield locus is named SI (after suction increase). Both, LC and SI yield loci enclose an elastic region in the $(p, s)$ plane (Fig. 6). Adopting a linear dependence between $v$ and $\ln \left(s+p_{\mathrm{a}}\right)$, both in the elasto-plastic and elastic range, one may write, for virgin states

$$
\mathrm{d} v=-\lambda_{\mathrm{s}} \frac{\mathrm{d} s}{\left(s+p_{\mathrm{as}}\right)}
$$

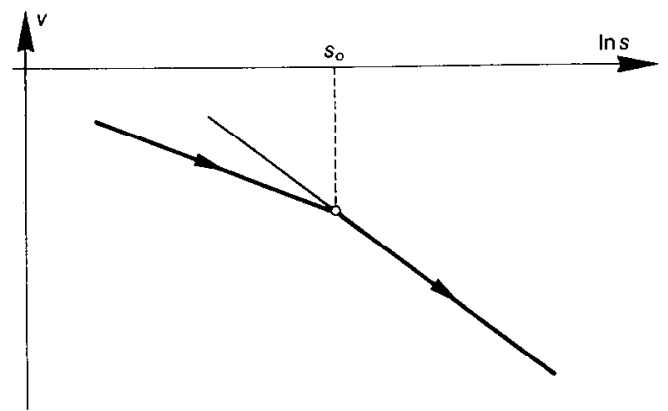

Fig. 5. Definition of yield suction $s_{n}$

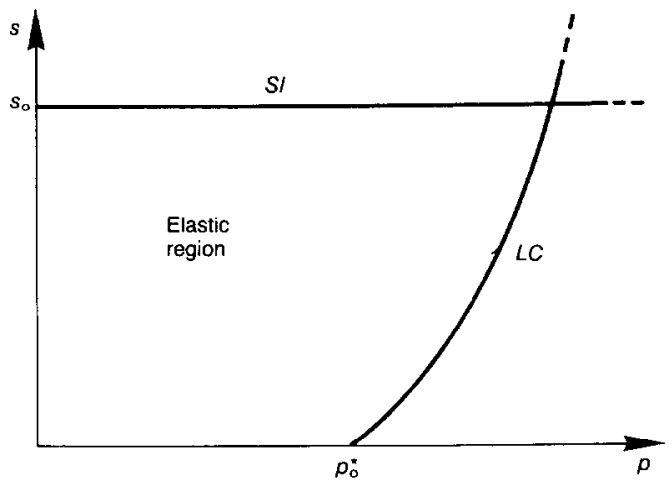

Fig. 6. Loading-collapse (LC) and suction increase (SI) yield curves 
For drying and wetting reversals

$$
\mathrm{d} v=-\kappa_{\mathrm{s}} \frac{\mathrm{d} s}{\left(s+p_{\mathrm{at}}\right)}
$$

which is, basically, Equation (4). However, some dependence of $\lambda_{\mathrm{s}}$ and $\kappa_{\mathrm{s}}$ on the net mean stress may be suspected but, for simplicity, they will be taken as constants.

\section{Hardening laws}

According to Equation (2), an increase of $p$ in the elastic region will induce a compressive (positive value) volumetric deformation given by

$$
\mathrm{d} \varepsilon_{\mathrm{vp}}{ }^{e}=-\frac{\mathrm{d} v}{v}=\frac{\kappa}{v} \frac{\mathrm{d} p}{p}
$$

Once the net mean stress $p$ reaches the yield value $p_{0}$ the total volumetric deformation may be computed from Equation (1)

$$
\mathrm{d} \varepsilon_{\mathrm{vp}}=\frac{\lambda(s)}{v} \frac{\mathrm{d} p_{0}}{p_{0}}
$$

and, therefore, the plastic component of volumetric strain will be given by

$$
\mathrm{d} \varepsilon_{\mathrm{vp}}{ }^{\mathrm{p}}=\frac{\lambda(s)-\kappa}{v} \frac{\mathrm{d} p_{0}}{p_{0}}
$$

Taking into account Equation (7) for the LC yield locus, it is simple to show that the plastic volumetric deformation (18) is also given by

$$
\mathrm{d} \varepsilon_{v p}{ }^{p}=\frac{\lambda(0)-\kappa}{v} \frac{\mathrm{d} p_{0}{ }^{*}}{p_{0}{ }^{*}}
$$

Similarly, an increase in suction within the elastic region will result in the volumetric strain (Equations (4) or (14))

$$
\mathrm{d} \varepsilon_{\mathrm{vs}}{ }^{\mathrm{e}}=\frac{\kappa_{\mathrm{s}}}{v} \frac{\mathrm{d} s}{\left(s+p_{\mathrm{at}}\right)}
$$

and, if the yield locus $s=s_{0}$ is reached, the following total and plastic deformations will be induced (Equation 13)

$$
\begin{aligned}
& \mathrm{d} \varepsilon_{\mathrm{vs}}=\frac{\lambda_{\mathrm{s}}}{v} \frac{\mathrm{d} s_{0}}{\left(s_{0}+p_{\mathrm{at}}\right)} \\
& \mathrm{d} \varepsilon_{\mathrm{vs}}{ }^{\mathrm{p}}=\frac{\lambda_{\mathrm{s}}-\kappa_{\mathrm{s}}}{v} \frac{\mathrm{d} s_{0}}{\left(s_{0}+p_{\mathrm{at}}\right)}
\end{aligned}
$$

Irreversible deformations control the position of the LC and SI yield surfaces through Equations (19) and (22). This type of hardening implies an independent motion of both yield curves in the $(p, s)$ stress space. However, some experimental evidence (Josa et al., 1987) suggests a definite coupling between them (see also Fig. 20 and its associated discussion in a later section). However, the different treatment given so far to the plastic deformations induced by suction or stress changes have only a formal meaning which has been useful to derive the appropriate relationships. It could be argued, as a first approximation, that both sets of plastic deformations have similar effects. In this manner, a simple way to couple both yield curves results if their position is controlled by the total plastic volumetric deformation, $\mathrm{d} \varepsilon_{\mathrm{v}}{ }^{\mathrm{p}}=\mathrm{d} \varepsilon_{\mathrm{vs}}{ }^{\mathrm{p}}+\mathrm{d} \varepsilon_{\mathrm{vp}}{ }^{\mathrm{p}}$. Then, from Equations (19) and (22) the proposed hardening laws are as follows

$$
\begin{aligned}
& \frac{\mathrm{d} p_{0}{ }^{*}}{p_{0}{ }^{*}}=\frac{v}{\lambda(0)-\kappa} \mathrm{d} \varepsilon_{\mathrm{v}}{ }^{\mathrm{p}} \\
& \frac{\mathrm{d} s_{0}}{s_{0}+p_{\mathrm{at}}}=\frac{v}{\lambda_{\mathrm{s}}-\kappa_{\mathrm{s}}} \mathrm{d} \varepsilon_{\mathrm{v}}{ }^{\mathbf{p}}
\end{aligned}
$$

\section{MODEL FOR TRIAXIAL STRESS STATES}

A third stress parameter, $q=\left(\sigma_{1}-\sigma_{3}\right)$, has to be incorporated to include the effect of shear stresses. The strain state is defined by $\varepsilon_{\mathrm{v}}\left(=\varepsilon_{1}\right.$ $\left.+2 \varepsilon_{3}\right)$, volumetric strain, and $\varepsilon_{\mathrm{s}}\left(=\frac{2}{3}\left(\varepsilon_{1}-\varepsilon_{3}\right)\right)$, shear strain. For consistency, the model must predict saturated behaviour when the value of suction reduces to zero. In accordance with the aim of simplicity, the saturated model adopted as a limit condition is a version of the modified Cam-clay model which gives an adequate qualitative description of saturated soil behaviour. The unsaturated formulation presented here could be coupled to more complex saturated models, achieving thus a better representation of some aspects of soil behaviour. However, given that the main aim of the model is the reproduction of the general behaviour of unsaturated soil, the selected saturated model is adequate for the purpose. Accordingly, it is proposed that the yield curve for a sample at constant suction $s$ will be described by an ellipse which will exhibit an isotropic preconsolidation stress given by the previously defined $p_{0}$ value which lies on the loading-collapse (LC) yield curve (Fig.7).

In order to define the ellipse it is also necessary to specify the failure states. In parallel with the saturated condition, a critical state line (CSL) for non-zero suction will represent the increased strength induced by suction. As a first hypothesis, the effect of suction will be represented by an increase in cohesion, maintaining the slope $M$ of the CSL for saturated conditions. As discussed previously this may be a suitable approach for a limited range of stress changes. Other choices are, however, possible.

If the increase in cohesion follows a linear relationship with suction, the ellipses will inter- 

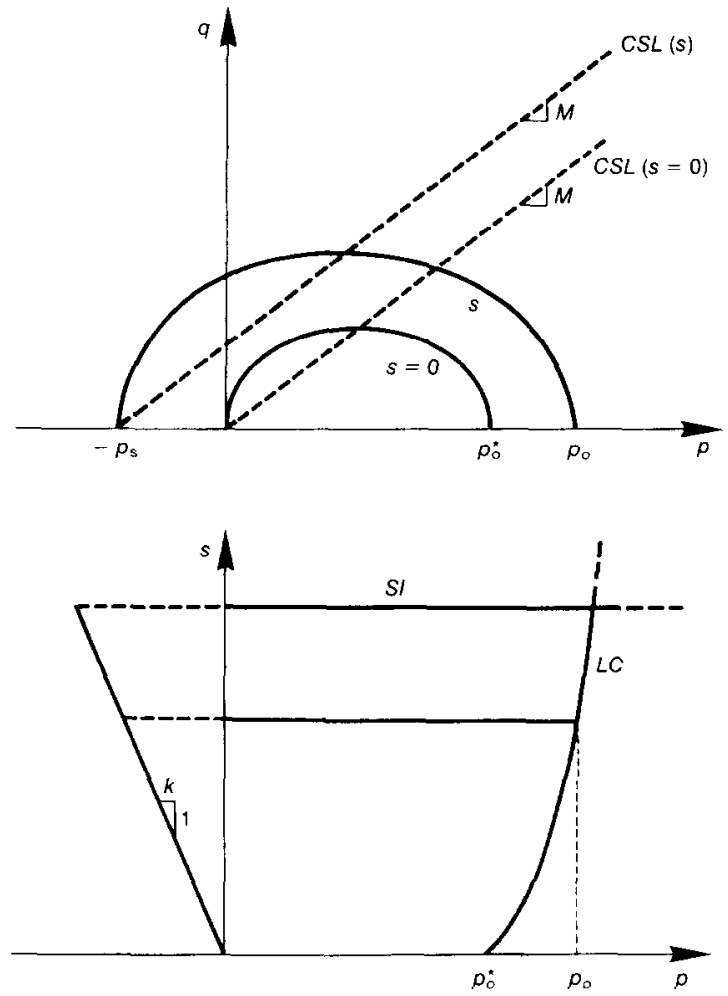

Fig. 7. Yield surfaces in $(p, q, s)$ space

sect the $p$ axis at a point for which

$$
p=-p_{\mathrm{s}}=-k s
$$

where $k$ is a constant. The major axis of the ellipse will span the segment $-p_{s}(s)$ to $p_{0}(s)$ and its equation will be given by

$$
q^{2}-M^{2}\left(p+p_{\mathrm{s}}\right)\left(p_{0}-p\right)=0
$$

It is also proposed that the yield locus SI extends into the region $q>0$ by means of a plane parallel to the $q$ axis, so that the Equation (13) is maintained in the $(p, q, s)$ space. A threedimensional view of the yield surfaces in the $(p, q, s)$ space is given in Fig. 8.

Regarding the direction of plastic strain increments, associated with the yield surface (26), a non-associated flow rule in the planes $s=$ constant is suggested. In fact, it is known (Gens \& Potts, 1982a) that conventional criticalstate models often overestimate $K_{0}$ values. To avoid this shortcoming, the expression for the associated flow rule is modified by introducing a parameter $\alpha$ (Ohmaki, 1982) resulting in the following equation

$$
\frac{\mathrm{d} \varepsilon_{\mathrm{s}}^{\mathrm{p}}}{\mathrm{d} \varepsilon_{\mathrm{vp}}^{\mathrm{p}}}=\frac{2 q \alpha}{M^{2}\left(2 p+p_{\mathrm{s}}-p_{0}\right)}
$$

where $\alpha$ is chosen in such a way that the flow rule predicts zero lateral strain for stress states corresponding to Jaky's (1948) $K_{0}$ values $\left(K_{0}=1-\sin \varphi^{\prime}=(6-2 M) /(6+M)\right)$. Given the relationship between $K_{0}$ and $M$ the new flow rule does not introduce any additional constitutive parameter. The components of the plastic strain associated with this yield surface will be given by $\left(\mathrm{d} \varepsilon_{\mathrm{yp}}{ }^{\mathrm{p}}, \mathrm{d} \varepsilon_{\mathrm{s}}{ }^{\mathrm{p}}\right)$. The expressions for these strain components can be derived by the application of standard procedures of strain hardening plasticity. For the second yield surface (Equation (13)), the vector of plastic strain increment induced by suction increase will be $\left(\mathrm{d} \varepsilon_{\mathrm{vs}}{ }^{\mathrm{p}}, 0\right)$, where $\mathrm{d} \varepsilon_{\mathrm{vs}}{ }^{\mathrm{p}}$ is given by Equation (22).

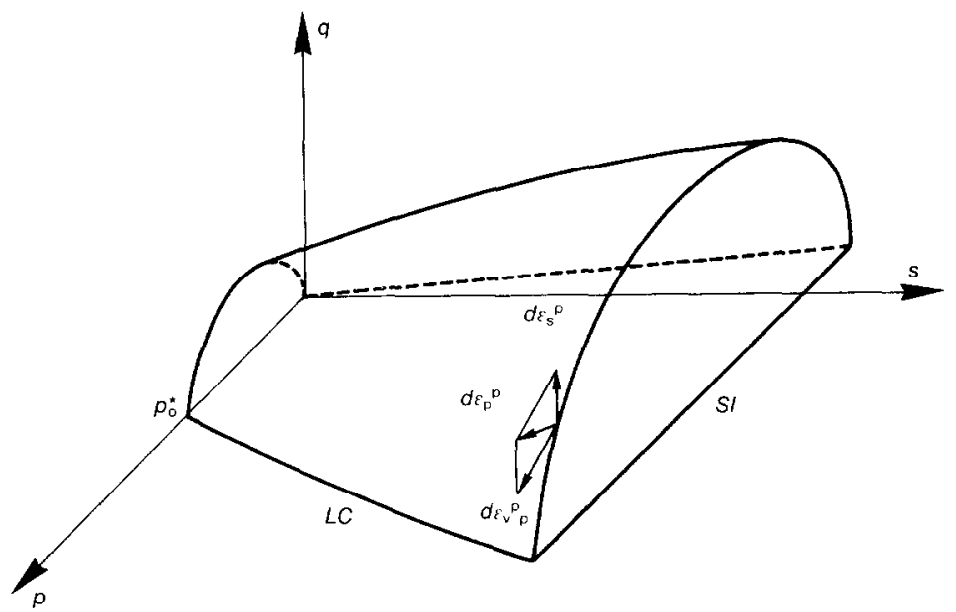

Fig. 8. Three-dimensional view of the yield surfaces in $(p, q, s)$ stress space 


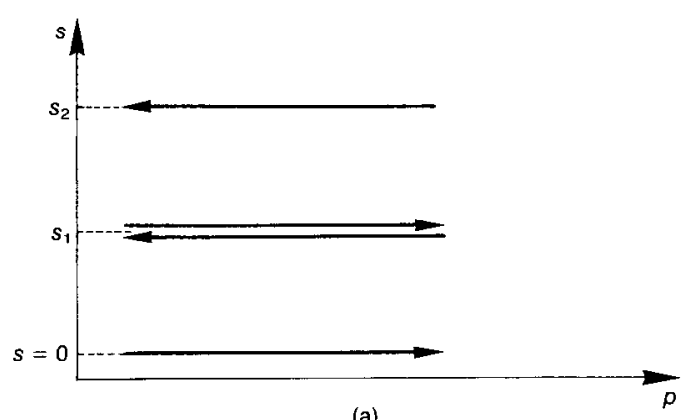

(a)

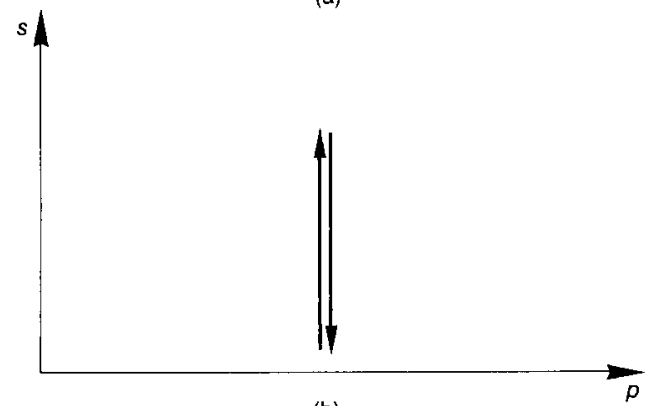

(b)

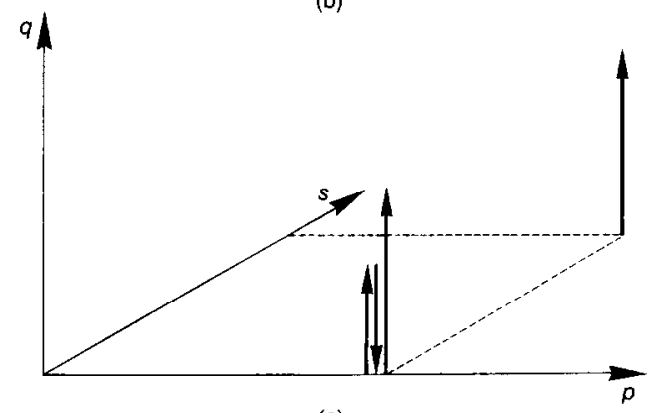

(c)

Fig. 9. Suitable stress paths to determine the model parameters

The elastic strains, $\mathrm{d} \varepsilon_{\mathrm{s}}{ }^{\mathrm{e}}=\frac{2}{3}\left(\mathrm{~d} \varepsilon_{1}{ }^{\mathrm{e}}-\mathrm{d} \varepsilon_{3}{ }^{\mathrm{e}}\right)$ induced by changes in $q$ will be computed through a shear modulus $G$

$$
\mathrm{d} \varepsilon_{\mathrm{s}}{ }^{\mathrm{e}}=\left(\frac{1}{3} G\right) \mathrm{d} q
$$

An ordered summary of the mathematical expressions defining the model are presented in Appendix 1. Extension to the three-dimensional principal stress space can be easily formulated (Gens \& Potts, 1988).

\section{PARAMETERS OF THE MODEL AND THEIR DETERMINATION}

The application of the model requires information on the following stress states and parameters.

(a) Initial state: initial stresses $\left(p_{\mathrm{i}}, q_{\mathrm{i}}, s_{\mathrm{i}}\right)$, initial specific volume $v_{0}$ and initial reference stress

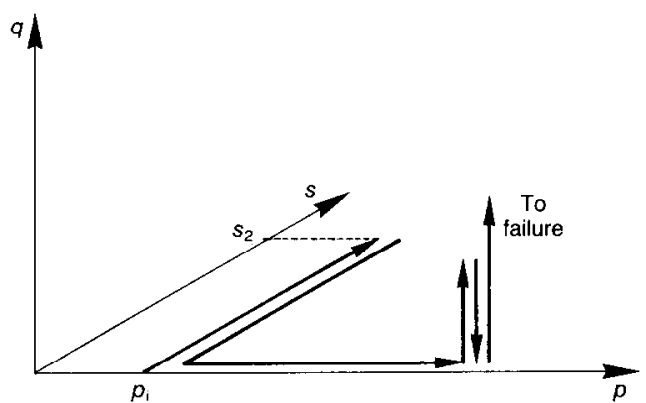

(a)

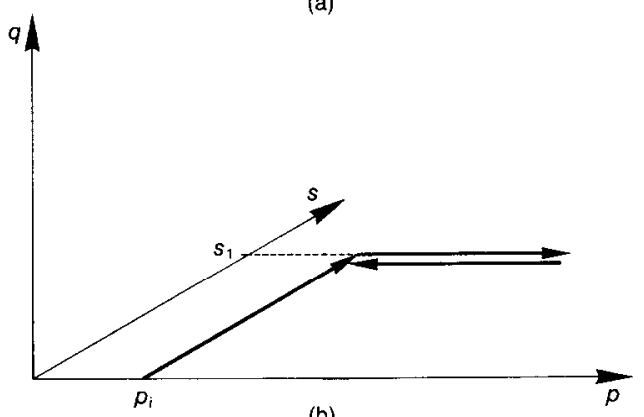

(b)

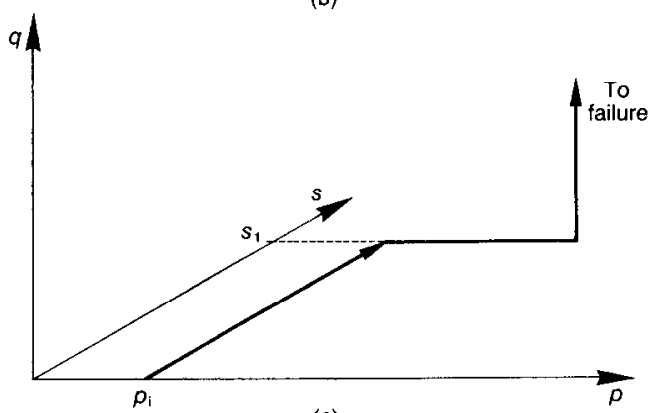

(c)

Fig. 10. Suggested tests to determine model parameters

variables (strain hardening parameters) defining the initial position of the yield surfaces $\left(p_{0 i}^{*}, s_{0 i}\right)$.

(b) Parameters directly associated with the LC yield curve (isotropic stress): $p^{c}$, reference stress; $\lambda(0)$, compressibility coefficient for the saturated state along virgin loading; $\kappa$, compressibility coefficient along elastic (unloading-reloading) stress paths; $r$, establishes the minimum value of the compressibility coefficient (virgin states) for high values of suction; $\beta$, controls the rate of increase in stiffness (virgin states) with suction.

(c) Parameters directly associated with changes in suction and the SI yield curve: $\lambda_{\mathrm{s}}$, compressibility coefficient for increments of suction across virgin states; $\kappa_{s}$, compressibility coefficient for changes in suction within the elastic region. 
(d) Parameters directly associated with changes in shear stress and the shear strength: $G$, shear modulus within the elastic domain; $M$, slope of the critical state lines; $k$, parameter that controls the increase in cohesion with suction.

A rational engineering approach requires the use of the simplest model compatible with the desired accuracy of results. A particular analysis of a given problem will involve some soil type and initial conditions and an estimation of expected stress paths. It may well happen that one of the proposed yield surfaces will never be reached. For instance, the behaviour of partially saturated non-expansive soils under paths which typically involve wetting and increase or decrease in mean and shear stress may be modelled by the LC yield curve and the associated yield surface in the $(p, q, s)$ space. The SI yield plane will not play any role in this case.

An example of this type may be found in the analysis of embankment dams in which the initial 'as-compacted' suction will not likely be increased. In this case the model requires nine parameters ( $p^{\mathrm{c}}, \lambda(0), \kappa, r, \beta, \kappa_{\mathrm{s}}, G, M, k$ ), five more than the parameters involved in a critical state model $(\lambda(0), \kappa, G$ and $M)$. The five additional parameters $\left(p^{\mathrm{c}}, r, \beta, \kappa_{\mathrm{s}}, k\right)$ allow for the modelling of typical patterns of the behaviour of partially saturated soil such as increasing stiffness and strength with increasing suction, collapse phenomena and (moderate) volumetric expansion when the soil is wetted. If drying processes are expected to influence the soil, a new parameter $\left(\lambda_{\mathrm{s}}\right)$ and the consideration of the SI yield surface may become necessary.

The determination of the model parameters will, in general, require suction-controlled testing. Suggested stress paths for different sets of parameters are the following (they have been indicated in Fig. 9)

(a) tests that involve isotropic drained compression (loading and unloading) at several constant suction values; they provide data to find $p^{\mathrm{c}}, p_{0}{ }^{*}, \lambda(0), \kappa, r$ and $\beta$ (Fig. 9a)

(b) tests that involve a drying-wetting cycle at a given net mean applied stress; they provide data to find $s_{0}, \lambda_{\mathrm{s}}$ and $\kappa_{\mathrm{s}}$ (Fig. $9 \mathrm{~b}$ )

(c) drained shear strength tests at different suction values; they provide data to determine $G, M$ and $k$ (Fig. 9c).

These basic stress paths may be combined into a few different tests necessary to obtain all the model parameters. Three tests which could lead to a full identification of the model are represented in Fig. 10. This is, of course, a minimum experimental programme. A more reliable deter- mination of parameters will certainly require more tests.

\section{TYPICAL FEATURES OF PREDICTED BEHAVIOUR}

Before a comparison is made with some experimental results, it is perhaps convenient to show the capabilities of the model by computing its predictions along a number of selected triaxial stress paths. In all the cases presented a single set of model parameters has been selected to describe a reference 'soil'. They are

(a) parameters directly associated with changes in $p$ and with the LC yield curve:

$$
\begin{aligned}
\lambda(0) & =0.2 ; \quad \kappa=0.02 ; \quad r=0.75 ; \\
\beta & =12.5 \mathrm{MPa}^{-1} ; \quad p^{c}=0.10 \mathrm{MPa}
\end{aligned}
$$

(b) compressibility coefficients for suction changes:

$$
\lambda_{\mathrm{s}}=0.08 ; \quad \kappa_{\mathrm{s}}=0.008
$$

(c) parameters directly associated with changes in shear stress and shear strength:

$$
G=10 \mathrm{MPa} ; \quad M=1 ; \quad k=0.6
$$

In addition, the initial void ratio was assumed to be $0.9(v=1.9)$. This ideal soil is a moderately compressible material. For large values of suction the compressibility against changes in $p$ is reduced to $75 \%$ of the saturated values. The angle of shearing resistance for saturated conditions is $25.4^{\circ}$ and the change in cohesion due to suction increase is moderate $(k=0 \cdot 6)$. For each of the examples presented the initial position of the yield curves LC and SI is indicated.

\section{Case 1, volumetric deformation induced by wetting} at increasing confining stress

The stress paths and the initial position of the yield LC and SI curves are indicated in Fig. 11a $\left(p_{0}{ }^{*}=0.20 \mathrm{MPa} ; s_{0}=0.3 \mathrm{MPa}\right)$. Three wetting paths-AB, CD and EF (1,2 and 3)-starting at an initial suction $s_{\mathrm{i}}=0.2 \mathrm{MPa}$ and three different confining stresses $(0.15 ; 0.35$ and $0.6 \mathrm{MPa})$ lead to the volumetric deformations plotted in Fig. 11(b). The first wetting path (AB) takes place within the elastic region and induces a continuous expansion (segment AB in Fig. 11(b)). The second wetting path, $\mathrm{CD}$, starts once a compression $\mathrm{AC}$ is applied to the sample. During wetting, a collapse of the sample starts at the beginning of suction reduction. The slight elastic expansion during path $C D$ is smaller than the compression induced by the motion of the LC curve to its final position and therefore a net collapse is computed. Finally, under path EF at a larger confining 


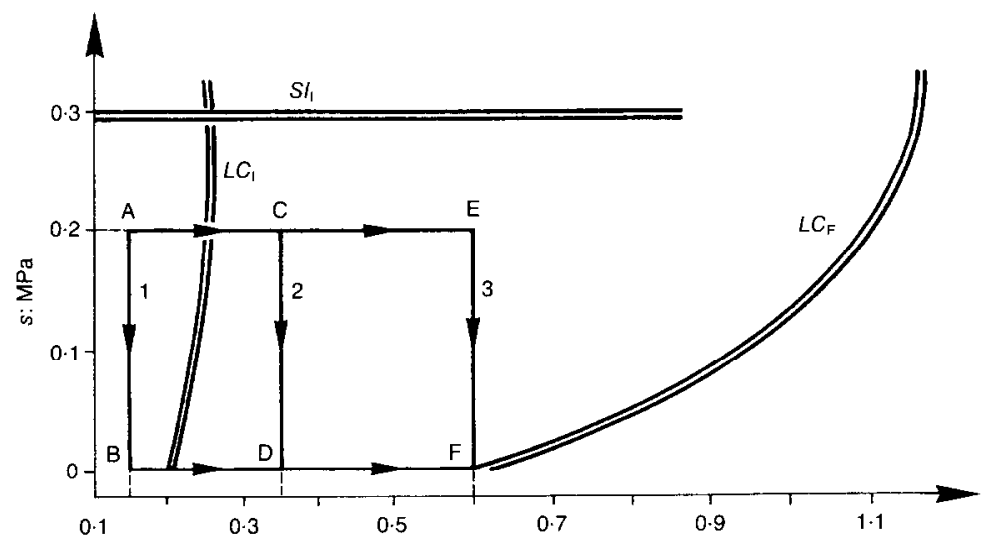

(a)

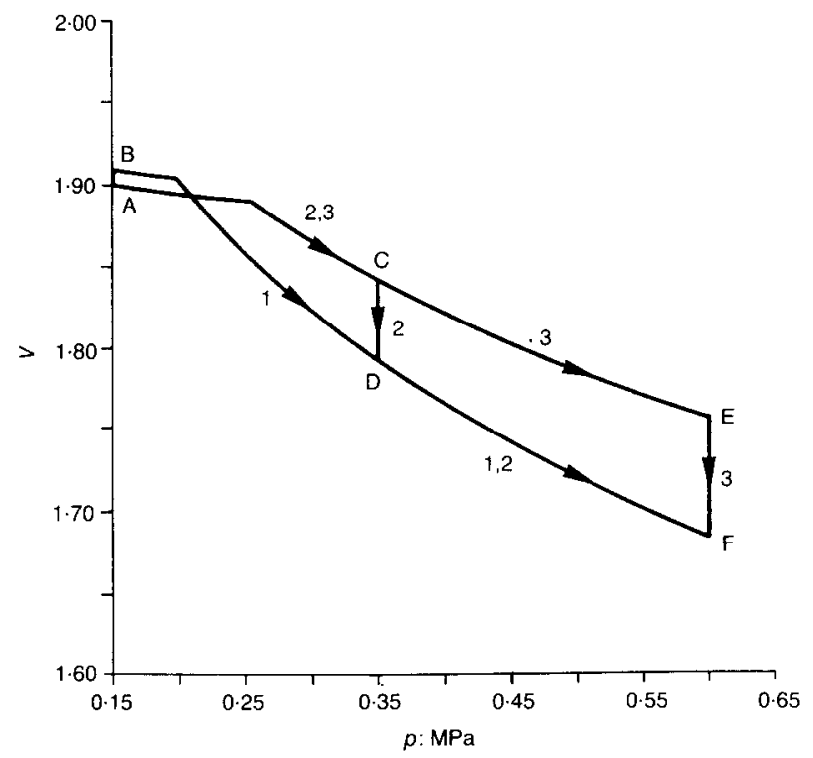

(b)

Fig. 11. Response of model to decreasing suction (wetting) at increasing net mean stress p: (a) stress paths; (b) specific volume-net mean stress relationships

stress, a larger collapse takes place (segment EF in Fig. 11(b)). Also, the compression curves, once the wetting is completed, follow a unique path for saturated conditions (path DF after wetting 2 follows the saturated compression curve BDF). Experimental results which favour this uniqueness have been reported by Jennings and Burland (1962) and Blight (1965) for collapsing sands, by Erol and El-Ruwaih (1982) testing loess and by Maswoswe (1985) in the case of a low plasticity sandy clay.

\section{Case 2, effect of alternate application of load and suction changes}

A first example is illustrated in Fig. 12(a). Beginning at the initial stress point $\mathrm{A}\left(s_{\mathrm{A}}=0 \cdot 2\right.$
$\mathrm{MPa}, p_{\mathrm{A}}=0 \cdot 15 \mathrm{MPa}$ ), three alternative loading stress paths $(1,2,3)$ which always involve a nonincreasing suction and a common final stress point, $s_{\mathrm{F}}=0$ and $p_{\mathrm{F}}=0.6 \mathrm{MPa}$, are represented. The initial position of the yield curves is given by $p_{0}{ }^{*}=0.20 \mathrm{MPa}$ and $s_{0}=0.3 \mathrm{MPa}$. The different combinations of $p$-loading and suction reduction, inducing either expansion $(\mathrm{A} \rightarrow \mathrm{C} \rightarrow \mathrm{E} \rightarrow \mathrm{F})$ or collapse $(A \rightarrow B \rightarrow D \rightarrow F)$, take the $L C$ yield curve to a final common position $\mathrm{LC}_{\mathrm{F}}$. The final volumetric deformation is the same under the three stress paths. These types of loading and suction change sequences lead to volume changes which are stress path independent and they have been used by some authors, quoted before, to formulate the volumetric behaviour of partially satu- 


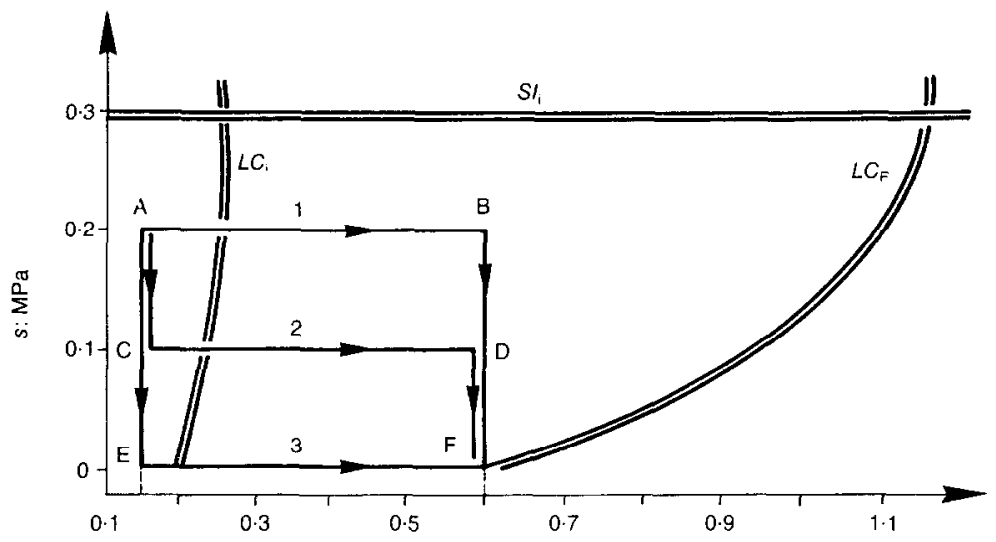

(a)

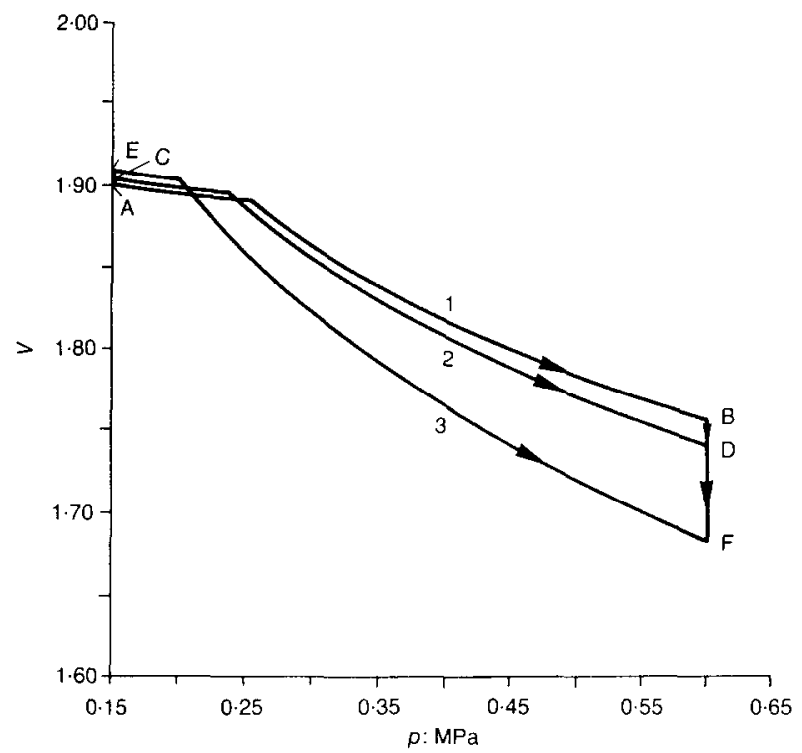

(b)

Fig. 12. Response of model to increments of net mean stress $p$ and decreasing suction (wetting): (a) stress paths; (b) specific volume-net mean stress relationships

rated soils in terms of state surfaces. Experimental results that involved stress paths qualitatively similar to the paths indicated in Fig. 12(a) were also reported by Barden et al. (1969) (group 2 tests) for low-plasticity clay. The pattern of model predictions agrees well with measured results.

Consider, however, stress paths which involve drying steps (Fig. 13). Three samples $(1,2,3)$ start now at a common stress point $\mathrm{A}\left(s_{\mathrm{A}}=0, p_{\mathrm{A}}=\right.$ $0.15 \mathrm{MPa})$ and are loaded and dried in three different sequences towards the final point $\mathrm{F}\left(s_{\mathrm{F}}=\right.$ $0.2 \mathrm{MPa} ; p_{\mathrm{F}}=0.6 \mathrm{MPa}$ ). The same initial preconsolidation state of the sample $\left(s_{0}=0.3 \mathrm{MPa}\right.$; $p_{0}{ }^{*}=0.2 \mathrm{MPa}$ ) as before is adopted in this case.
Sample 1, loaded under saturated conditions, displaces the yield $L C$ curve to the position $L_{B}$ and then experiences an elastic decrease in volume when suction is increased from $B$ to $F$, without any further change of the position of the LC curve. This sample experiences the largest volumetric deformation of the three. Under path 3, the suction applied from $A$ to $E$ induces some compression of the sample and an increase in stiffness against the subsequent increase of confining stress. The stress path EF displaces the LC yield curve to the final position $L_{\mathrm{F}}$ at a reference $p_{\mathrm{OF}}{ }^{*}<p_{\mathrm{OB}}{ }^{*}=0.6 \mathrm{MPa}$. It will experience the smallest volumetric deformation as Fig. 13(b) 


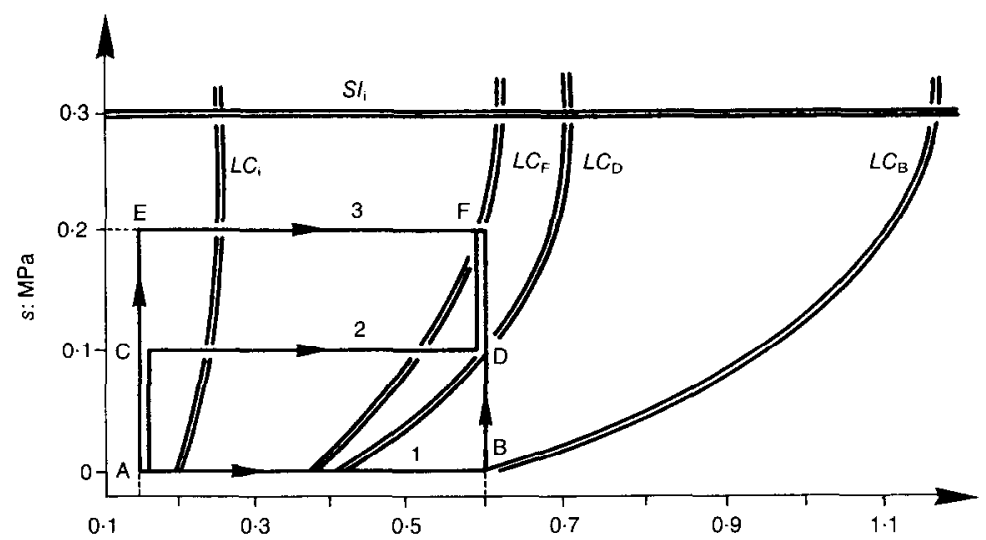

(a)

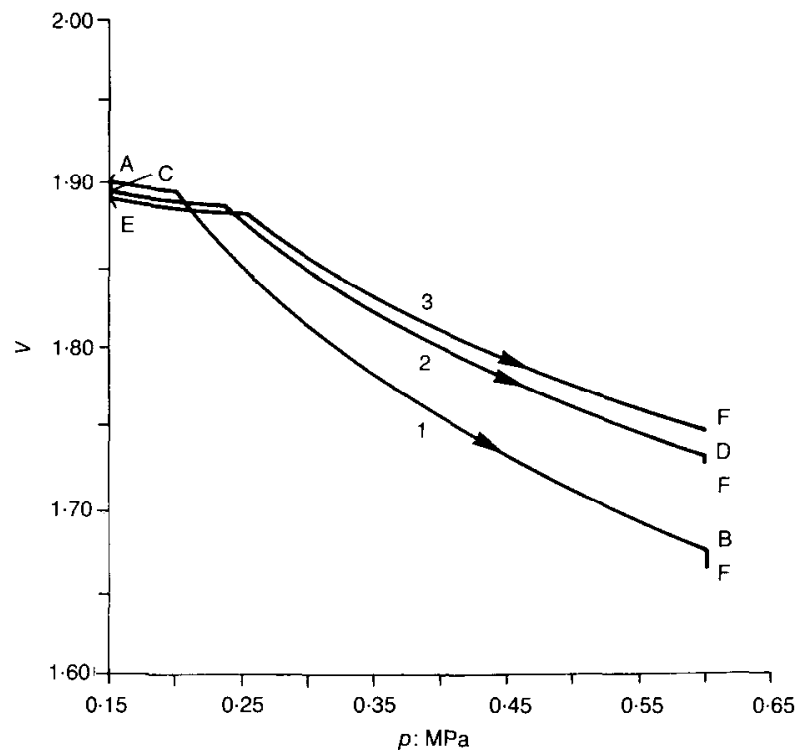

(b)

Fig. 13. Response of model to increments of net mean stress $p$ and increasing suction (drying): (a) stress paths; (b) specific volume-net mean stress relationships

indicates. The paths which involve drying before subsequent $p$-loading are therefore stress path dependent. This conclusion was also reached in the experimental work reported by Barden et al. (1969) testing low plasticity clay, Matyas \& Radhakrishna (1968) testing a low plasticity sandy clay and Josa et al. (1987) testing kaolin.

\section{Case 3, coupling of the SI and LC yield curves}

In the preceding two cases the SI yield curve did not play any role in the model predictions since the applied suctions were smaller than $s_{0}$.
In Fig. 14, a p-loading path $\mathrm{AB}$ at a constant suction $\left(s_{\mathrm{A}}=0 \mathrm{MPa}\right)$ is compared with a similar loading (DE) preceded in this latter case by a drying-wetting cycle (ACD) in which a maximum suction of $0.3 \mathrm{MPa}$ is applied. The initial yield curves are characterized by $p_{0}{ }^{*}=0.2 \mathrm{MPa}$ and $s_{0}=0.025 \mathrm{MPa}$. The drying-wetting cycle induces a net compaction of the sample and the irreversible path of this deformation moves $\mathrm{LC}_{\mathrm{i}}$ to the position $\mathrm{LC}_{\mathrm{D}}$ shown in Fig. 14(a). On subsequent $p$-loading, path $D E$, the sample experiences a larger preconsolidation stress than the sample subjected to path AB (Fig. 14(b)). Experimental indication of this type of behaviour may 


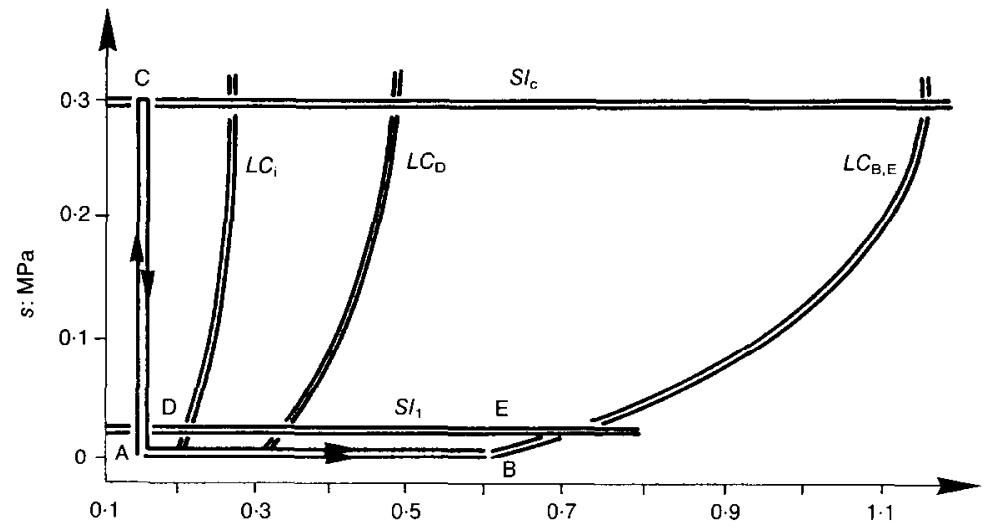

(a)

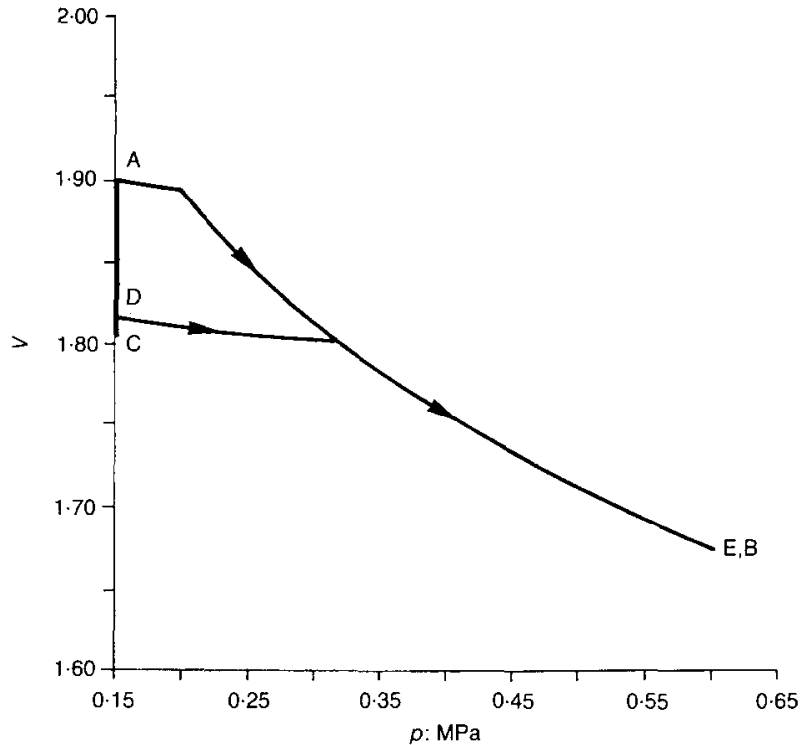

(b)

Fig. 14. Effect of initial increase of suction: (a) stress paths; (b) specific volume-net mean stress relationships

be found in the experimental work of Josa et al. (1987).

\section{Case 4, shear tests for different suctions}

Three shear tests maintaining a constant net mean stress $p_{\mathrm{A}}=0.15 \mathrm{MPa}$, for three different suctions $\left(s_{1}=0.10 \mathrm{MPa}, s_{2}=0.20 \mathrm{MPa}, s_{3}=\right.$ $0.30 \mathrm{MPa}$ ) are indicated in Fig. 15. The initial yield curves LC and SI $\left(p_{0}{ }^{*}=0.15 \mathrm{MPa}, s_{0}=0.4\right.$ $\mathrm{MPa}$ ) are shown in Fig. 15(a). The shear stressshear strain relationships computed in the three cases are plotted in Fig. 15(b). These curves show an increase in strength with suction. Results of this kind have been reported by Delage et al. (1987) testing silt in a suction controlled triaxial cell.
Case 5, failure under decreasing suction

A stress path to illustrate the possibility of failure of a stressed partially saturated soil due to suction reduction is indicated in Fig. 16. This type of failure is probably significant in slopes located in partially saturated soils (i.e. slopes in residual soils in tropical regions) subjected to wetting due to infiltration from rainfalls (Brand, 1981). In the case analysed the suction was first increased at constant net mean stress (path $\mathrm{AB}$ ), then the net mean stress was increased at constant suction (BC), a deviatoric stress was applied (CD) and the suction was finally reduced until failure was achicved (DE). The initial positions of the yield curves LC and SI are plotted in Fig. 


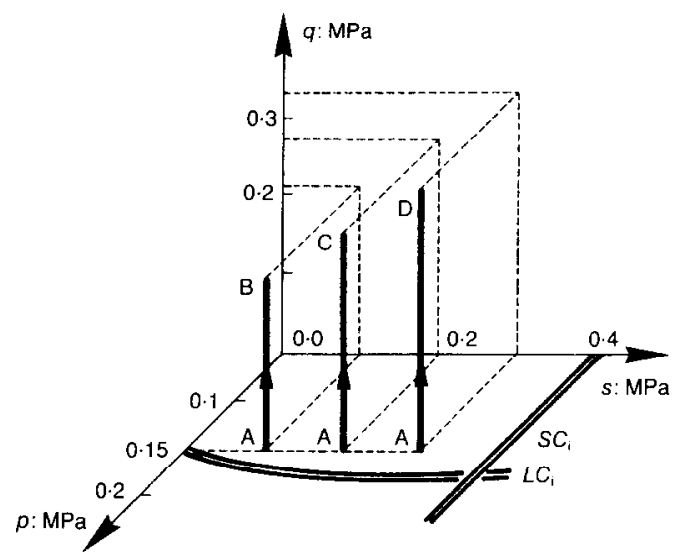

(a)

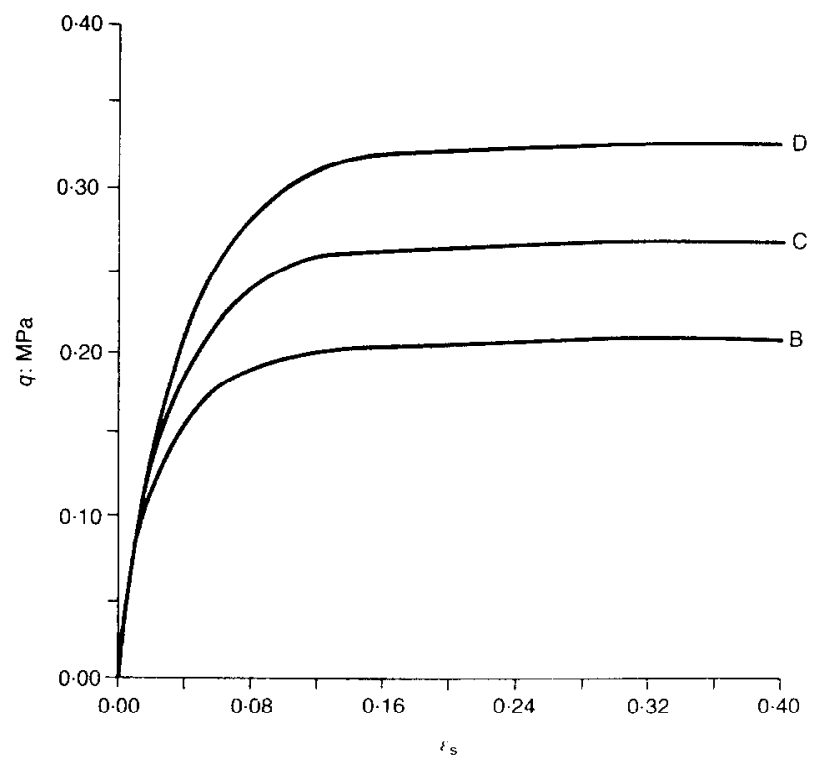

(b)

Fig. 15. Response of model to shear tests at different suctions: (a) stress paths; (b) shear stress-shear strain relationships

$16(\mathrm{a})\left(p_{0}{ }^{*}=0.15 \mathrm{MPa} ; s_{0}=0.3 \mathrm{MPa}\right)$. The effect of final wetting (DE) in terms of change in shear strain is plotted in Fig. 16(b). Failure takes place at a final suction $s_{\mathrm{F}}=0.033 \mathrm{MPa}$.

\section{COMPARISON OF MODEL PREDICTIONS} WITH EXPERIMENTAL RESULTS

Tests on partially saturated compacted kaolin reported by Josa (1988)

Details of the tests performed on partially saturated compacted kaolin are given elsewhere (Josa et al., 1987; Josa, 1988) and only a brief summary is given here. A stress-path triaxial cell was suitably modified to induce suction states in the pore water. This was achieved by applying a constant air pressure in the upper porous stone and a variable water pressure in the lower stone. Load and deformation measurements were made inside the testing chamber. Pore and confining pressures as well as vertical load were applied by means of mercury pots whose position was controlled by stepper motors. A computer, linked to the system, controlled the predefined stress and suction path 


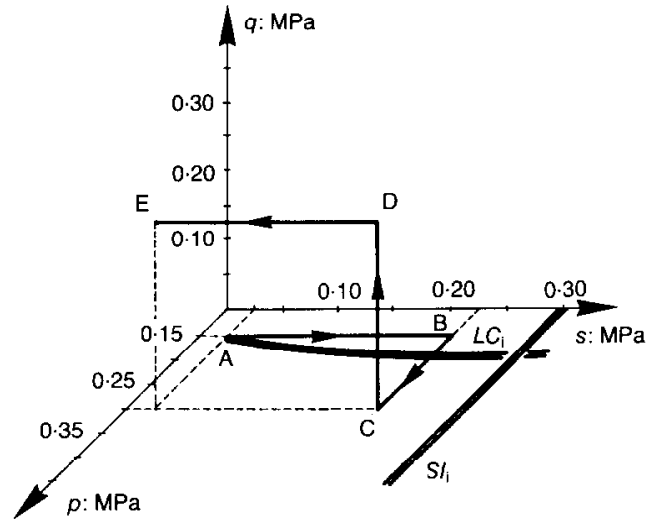

(a)

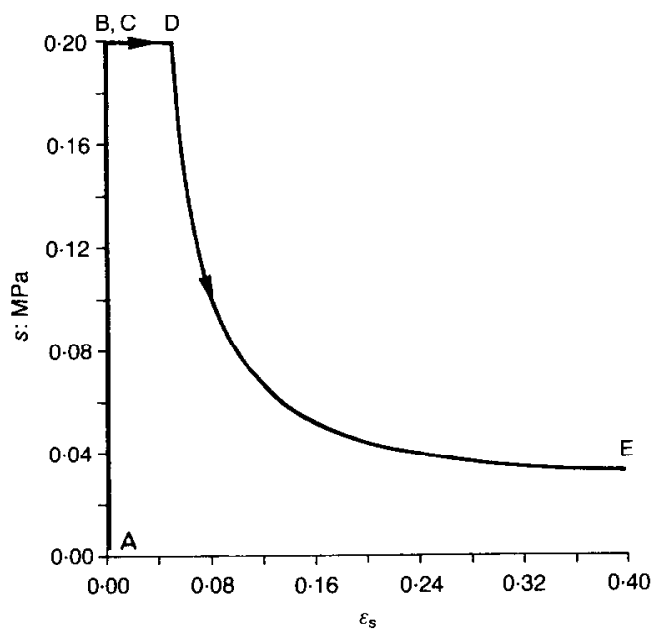

(b)

Fig. 16. Response of model to test in which failure is induced by decreasing suction (wetting): (a) stress paths; (b) suction-shear strain relationship

through the necessary feedback of measured performance.

The soil used in the tests was a commercially available kaolin moderately plastic $\left(w_{\mathrm{L}}=38.7 \%\right.$; $w_{\mathrm{P}}=26.9 \% ; \%$ particles $\leqslant 2 \mu: 4 \%$; $\%$ particles $\leqslant$ No. 200 ASTM: $95 \%$; uniformity coefficient: 2; Universal Classification: ML). Main mineral components were quartz and kaolinite. A moderate percentage of illite was also found in $\mathrm{X}$-ray diffraction tests. Samples were compacted by kneading and then allowed to consolidate to an initial stress state given by $p=0.045 \mathrm{MPa}$; $s=0.01 \mathrm{MPa}$ and $q=0$. Once consolidated, they reached $e_{0}=0.915$ and $S_{\mathrm{r} 0}=0.875$. From this state the subsequent application of a desired stress path was carried out.

The parameters controlling the variation of soil stiffness with suction $(\lambda(0), r$ and $\beta$; see Equation
(12)) can be obtained by means of isotropic compression tests at different constant suctions. Tests of this kind are shown in Fig. 17(a). In Fig. 17(b) the variation of $\lambda(s)$, computed through Equation (17) was plotted in terms of $p$. Three $\lambda(s)$ values were obtained $(\lambda(0.04)=0.09 ; \lambda(0.06)=0.075$ $\lambda(0.09)=0.06)$ from the final horizontal sections of the curves which relate to samples loaded beyond their preconsolidation pressure. They allow the determination of the three unknowns $\lambda(0), r$ and $\beta$ through Equation (12). It was found $\lambda(0)=0.14 ; \beta=16.4 \mathrm{MPa}^{-1}$ and $r=0.26$. Also, an average value $\kappa=0.015$, was measured under unloading paths.

In order to obtain $\lambda_{\mathrm{s}}$ and $\kappa_{\mathrm{s}}$, tests involving the application of suction cycles at a constant net mean stress $p$, are ideally suited, provided the

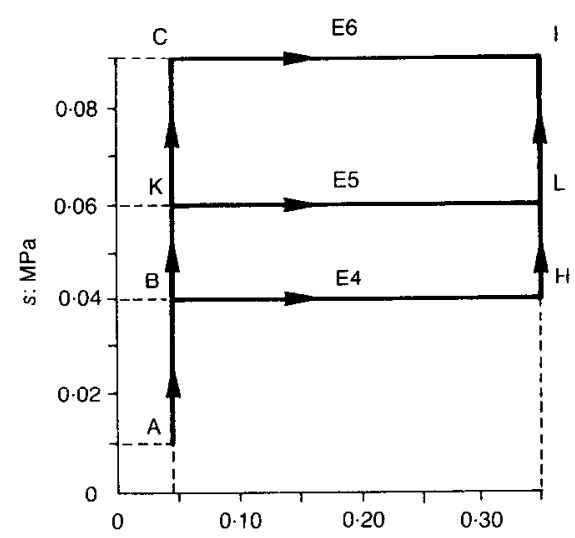

(a)

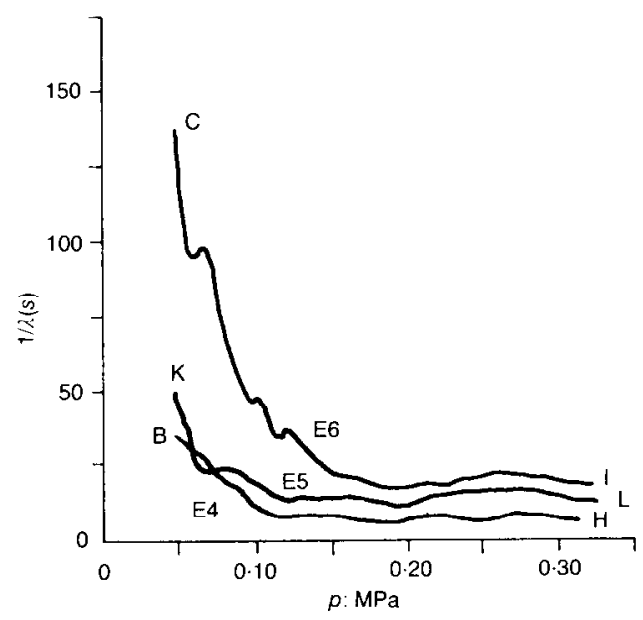

(b)

Fig. 17. Isotropic compression tests of partially saturated compacted kaolin: (a) stress paths; (b) variation of soil compressibility 
suction decrease path does not intersect the LC yield locus. This may be achieved if the suction is first increased and then decreased, at a constant net mean stress. A test of this kind is represented in Fig. 18. It shows a quasi-elastic response of the soil beyond the first suction increase, as suggested by the model proposed. Several tests of this kind provided the following average parameter values: $\lambda_{\mathrm{s}}=0.05$ and $\kappa_{\mathrm{s}}=0.01$.

The shear modulus $G$ was obtained in drained tests involving the application of a deviatoric stress $q$ at different values of net mean stress and suction. The stress paths selected and the measured shear stress-strain relationships are given in Figs 22(a) and (b) respectively (these tests will be used subsequently to compare with model predictions). As a consequence of the flow rule assumed, no plastic shear strains occur at the start of the test, so the initial part of the stressstrain curves can be used to determine the elastic shear modulus $G$. A value of $3.3 \mathrm{MPa}$ was obtained.

Several shear strength tests were performed at different values of $p$ and $s$ (Fig. 19). Within the

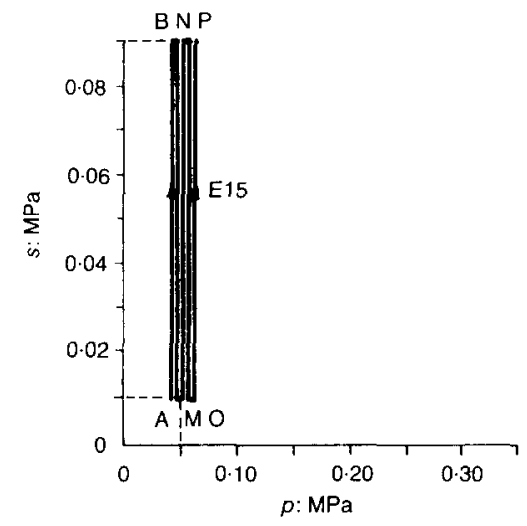

(a)

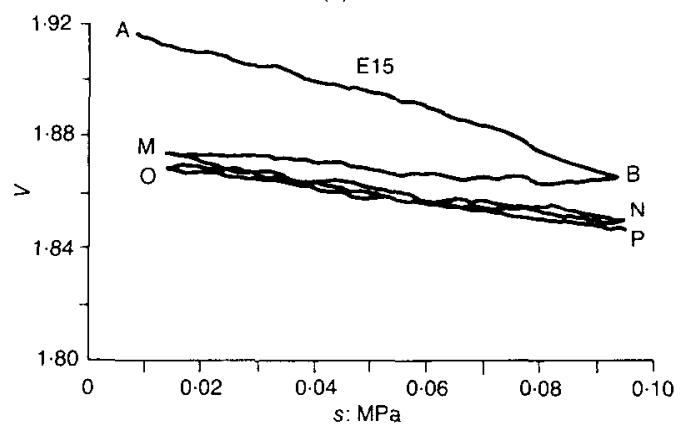

(b)

Fig. 18. Effect of cycles of applied suction on changes in specific volume of isotropically confined partially saturated compacted kaolin: (a) stress paths; (b) experimental results

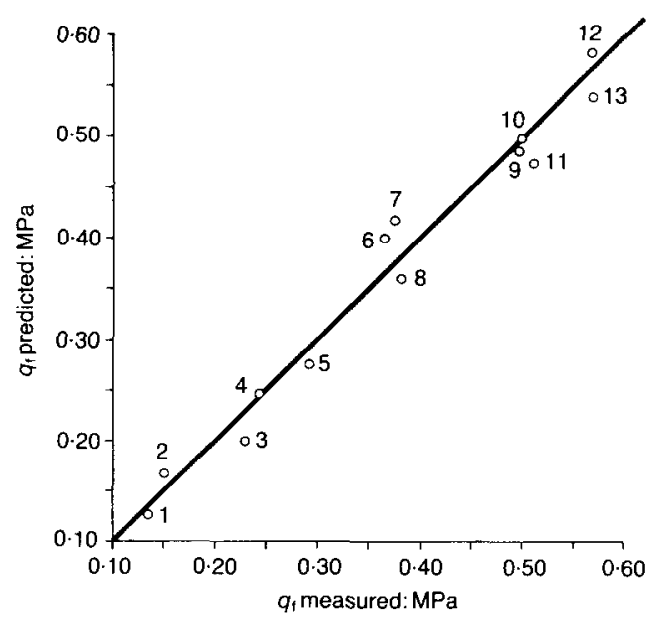

\begin{tabular}{l|c|c}
\hline Test & $\begin{array}{c}p: \\
\mathrm{MPa}\end{array}$ & $\begin{array}{c}s: \\
\mathrm{MPa}\end{array}$ \\
\hline 1 & 0.142 & 0.0097 \\
2 & 0.142 & 0.0142 \\
3 & 0.137 & 0.0950 \\
4 & 0.280 & 0.0160 \\
5 & 0.340 & 0.0000 \\
\hline 6 & 0.475 & 0.010 \\
7 & 0.390 & 0.095 \\
8 & 0.325 & 0.091 \\
9 & 0.544 & 0.040 \\
10 & 0.557 & 0.041 \\
\hline 11 & 0.558 & 0.016 \\
12 & 0.590 & 0.097 \\
13 & 0.540 & 0.095 \\
\hline
\end{tabular}

Fig. 19. Comparison between measured $q_{\mathrm{f}}$ values and predicted shear strength assuming critical state plane in the $(p, q, s)$ space

range of stresses applied ( $s=0$ to $0.097 \mathrm{MPa}$ and $p=0.137$ to $0.59 \mathrm{MPa}$ ) the plane

$$
q=M p+M k s=0.821 p+1 \cdot 022 s
$$

fits the results with a standard deviation of $6.8 \%$ (Fig. 19). This plane provides the constants $M=0.821$ and $k=1 \cdot 245$.

The initial position of the yield surface is governed by the reference stress variables $p_{0}{ }^{*}$ and $s_{0}$. $p_{0}{ }^{*}$ may be obtained if there is information concerning the yield stress under increasing $p$. In our case, this information is provided by the tests reported in Fig. 17. A relatively sudden change in $1 / \lambda(s)$ with $p$ provides an estimation of $p_{0}$. Although it is difficult to pinpoint exactly the position of the yield point, the following values can perhaps be identified from Fig. 17(b): $p_{0}(0.04)=0.065 \mathrm{MPa} ; p_{0}(0.06)=0.07 \mathrm{MPa} ;$ $p_{0}=(0.09)=0.085 \mathrm{MPa}$. These values have been used to compute $p_{0}{ }^{*}$ and $p^{\mathrm{c}}$ through Equation (7). $A$ least squares error prediction procedure leads to $p_{0}{ }^{*}=0.055 \mathrm{MPa}$ and $p^{\mathrm{c}}=0.043 \mathrm{MPa}$. In 
addition, tests in which suction was increased, thus maintaining a constant net mean stress $p$, equal to the initial value, could be interpreted in a similar way (test E1 in Fig. 20). It was found $s_{0}=$ $0.03 \mathrm{MPa}$. A second test (E3) represented in Fig. 20 shows an apparent increase in $s_{0}$ when the sample has undergone a previous increase in net mean stress $p$ (path $\mathrm{AC}$ ). This result suggests a coupling between the yield loci LC and SI as proposed in the model.

A summary of model parameters and initial and reference conditions is given in Table 1.

The stress paths followed by two tests (E5 and E6) in the plane $q=0$ are represented in Fig. 21. The measured volumetric deformations of the two samples (in terms of $v$ ) and the model predictions using the parameters given in Table 1 are plotted in Fig. 21. In these two tests the samples are subjected to ever increasing changes in net mean

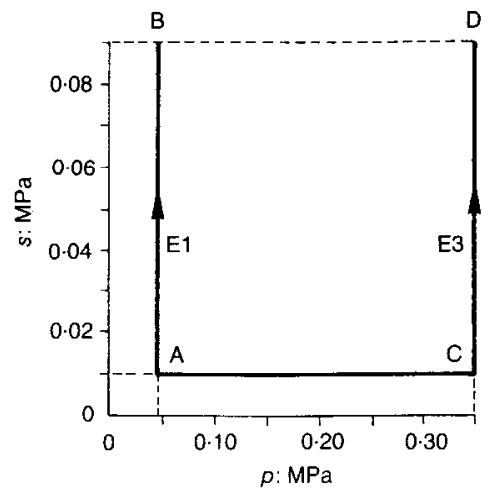

(a)

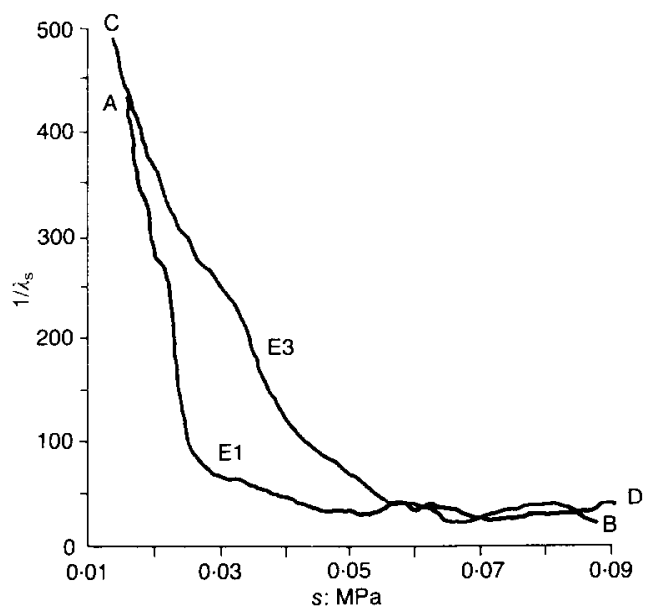

(b)

Fig. 20. Tests on partially saturated compacted kaolin involving increase in suction: (a) stress paths; (b) Variation of soil compressibility with applied suction

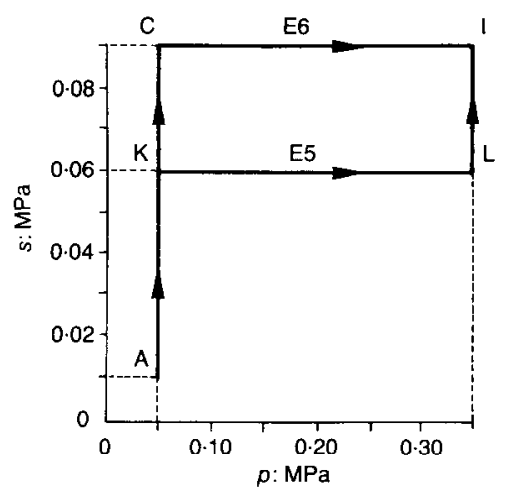

(a)

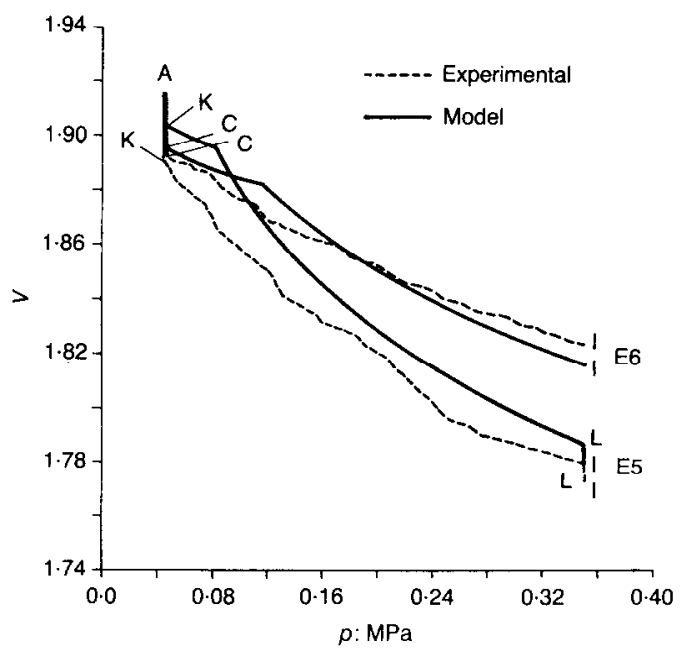

(b)

Fig. 21. Comparison between measured and predicted results for partially saturated compacted kaolin under isotropic stress changes: (a) stress paths; (b) variation of specific volume with net mean stress

stress and suction along different paths. Fig. 21 shows a rcasonably good prediction.

A second example, involving the application of deviatoric stresses, is given in Fig. 22. The results of two tests-test F18 (path C.Z) and test E11 (path $\mathrm{JZ}$ ) - are compared with model predictions. Test E18 involves the application of $q$ maintaining $\mathrm{d} p=0$. In test $\mathrm{E} 11, \mathrm{~d} \sigma_{3}=0$. In both tests the samples reached failure. The comparison between measured and predicted shear stressshear strain relationships is given in Fig. 22(b). In general terms, a good correspondence is obtained.

Tests on partially saturated compacted sandy clay reported by Maswoswe (1985)

Maswoswe (1985) reports several suction controlled oedometer and triaxial tests of low plasticity sandy clay (Lower Cromer till) having the 


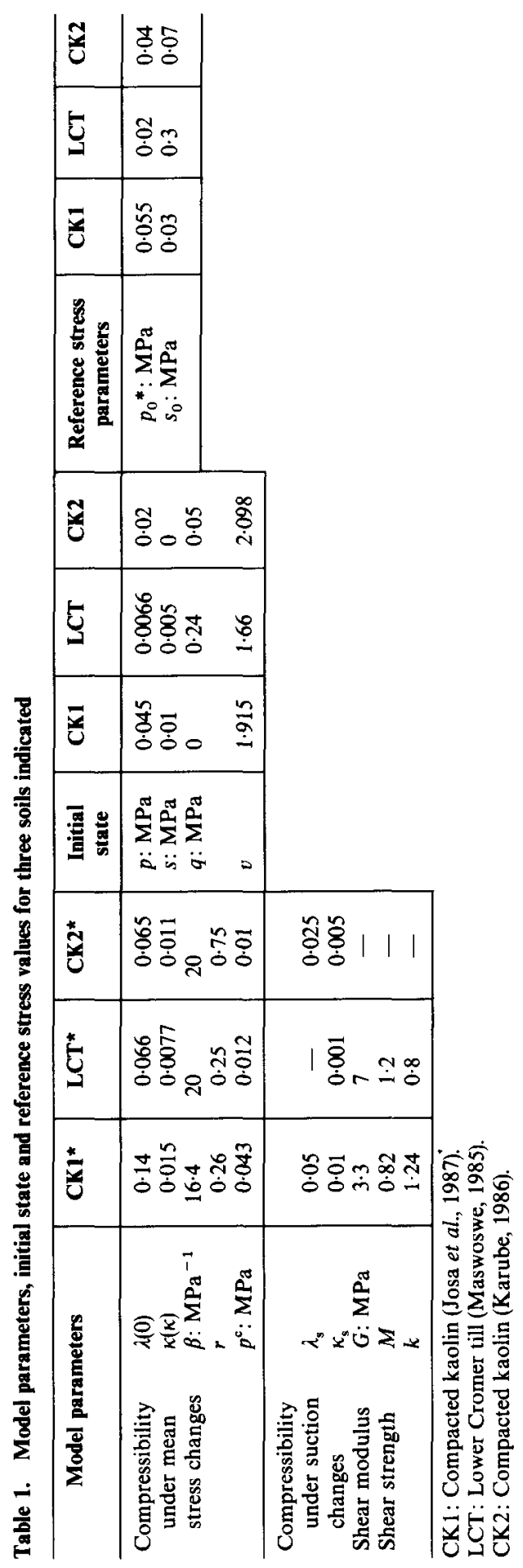




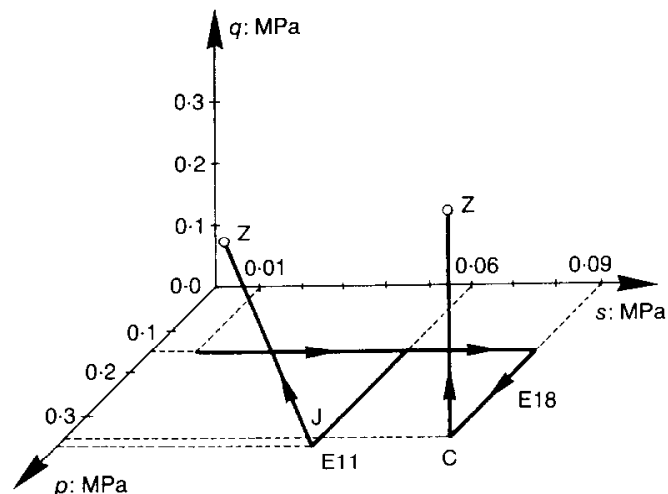

(a)

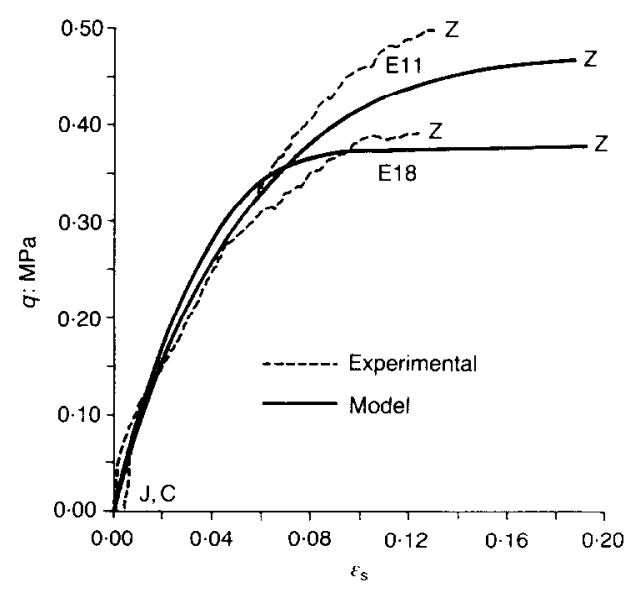

(b)

Fig. 22. Shear tests on partially saturated compacted kaolin: (a) stress paths; (b) comparison of measured and predicted shear stress-shear strain relationships

following characteristics: $w_{\mathrm{L}}=25 \% ; w_{\mathrm{P}}=12 \%$; clay content: $17 \%$; percentage of sand $>50 \%$; clay activity $=0.71$. Samples were statically compacted, dry of optimum.

An important aim of the research work reported by Maswoswe (1985) was to determine the stress path followed by the soil during collapse under oedometric conditions (no lateral deformation). Accordingly, the radial deformation of the samples in the triaxial tests was constantly monitored and the stress state was modified to ensure zero lateral deformation. The results of a particularly relevant test in which a sample was first subjected to an increase in vertical stress under constant water content and subsequently wetted under constant vertical stress were selected for comparison with the model developed. The stress path followed by the sample is shown in Fig. 23 in a plane $\left(\sigma_{1}-u_{a}, s\right)$. Measured behav-

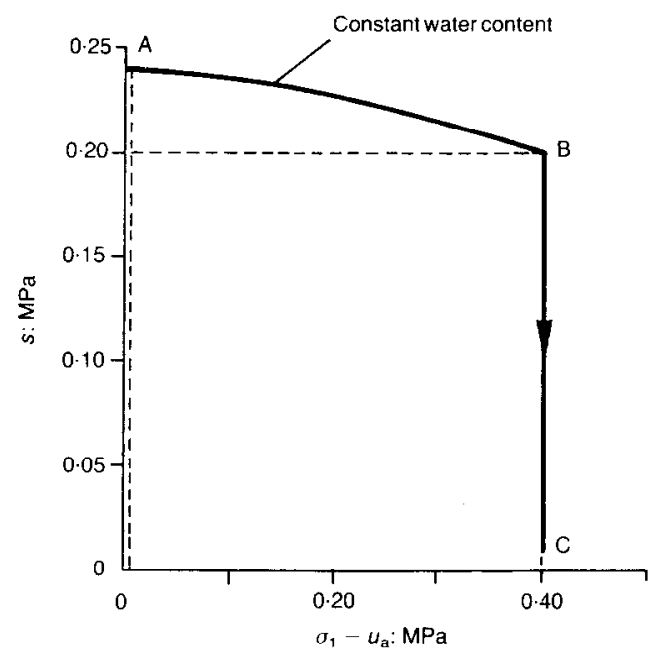

Fig. 23. Stress path followed by sample of sandy clay (Lower Cromer till) tested by Maswoswe (1985) (test SK3)

iour of the sample in terms of variation of void ratio with vertical stress and in terms of the stress path followed by the soil in the planes $\left(\left(\sigma_{1}\right.\right.$ $\left.\left.+\sigma_{3}\right) / 2-u_{\mathrm{w}},\left(\sigma_{1}-\sigma_{3}\right) / 2\right)$ and $\left(\left(\sigma_{1}+\sigma_{3}\right) / 2-u_{\mathrm{a}}\right.$, $\left.\left(\sigma_{1}-\sigma_{3}\right) / 2\right)$ are plotted in Fig. 24(a and b).

The tests performed by Maswoswe (1985) are not well suited to determine, in a direct way, the parameters of the proposed model. In particular, the loading test under constant water content are difficult to interpret as the saturation of the sample increases with the load and therefore 'pure' compression behaviour and collapse phenomena may coexist in the sample along the same stress path. Fortunately, some basic parameters of saturated compacted Lower Cromer till have been reported by independent studies (Gens, 1982; Gens \& Potts, 1982b). The following values were taken from this work: $\lambda(0)=0.066$; $\kappa=0.0077 ; M=1 \cdot 2$. They have been selected for the purposes of the present comparison as they appear to fit well the behaviour of the soil saturated after compaction.

Other model parameters could not be obtained directly from Maswoswe's results. However, the observed trends of behaviour have been used to obtain approximate values for the unknown parameters. For instance, the collapsing properties of the soil tested are relatively important and therefore a low value for $r(r=0.25)$ was adopted. On the other hand, the increase in stiffness with suction is relatively marked and this is reflected in the selected values $\beta=20 \mathrm{MPa}^{-1}$, and $k=0.8$. The test to be modelled (test SK3, Fig. 24(a)) indicated an apparent preconsolidation net mean stress $p_{0}=0.2 \mathrm{MPa}$ for a suction close to 


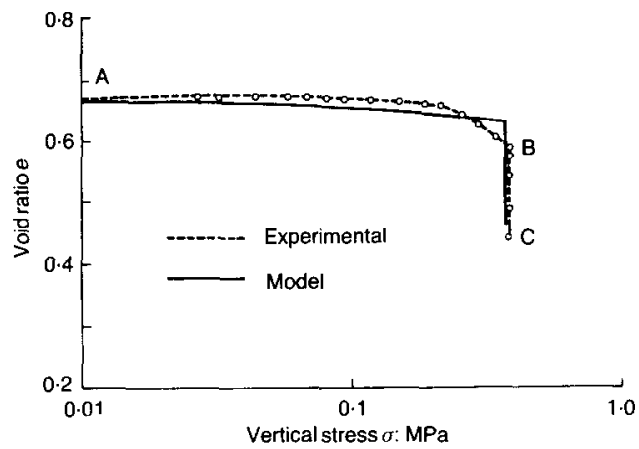

(a)

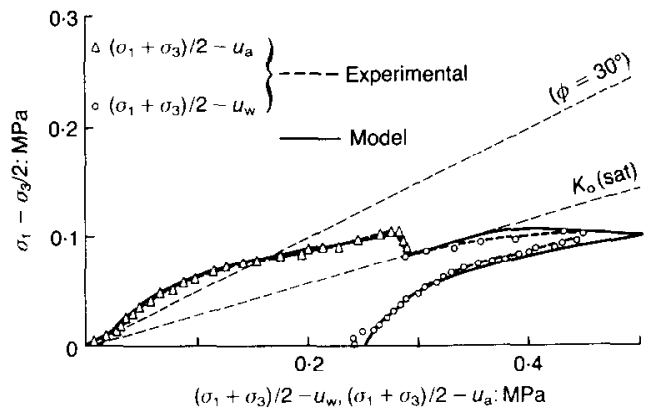

(b)

Fig. 24. Results reported by Maswoswe (1985) (Test SK3) and model predictions: (a) variation of void ratio with vertical stress; (b) stress paths in the triaxial plane

$s=0.22 \mathrm{MPa}$. Oedometer tests on saturated samples prepared in the same way and with the same initial conditions showed preconsolidation stresses significantly lower, around $p_{0}{ }^{*}=0.02$ $\mathrm{MPa}$. These results, interpreted through Equation (7), provide a value $p^{c}=0.012 \mathrm{MPa}$ for the reference stress. Again due to the significant collapsing characteristics of the tested soil, it is difficult to isolate recoverable volumetric strains along the wetting paths. It is thought that, given the type of soil and the rigid open structure likely to develop in the process of static compaction dry of optimum, the value of $\kappa_{\mathrm{s}}$ will probably be very small. Therefore $\kappa_{\mathrm{s}}$ was selected equal to 0.001 .

In his experimental work on saturated compacted Lower Cromer till, Gens (1982) proposed a variation of $G$ with the maximum previous effective preconsolidation stress $p_{0}{ }^{\prime}, G=93.4 p_{0}{ }^{\prime}$. It is unclear to what extent could this expression, valid for saturated conditions, be used for a partially saturated soil. Thinking in terms of the proposed model, given an apparent preconsolidation stress $p_{0}$, the wetter the soil (i.e. the lower the suction), the smaller its specific volume. This probably indicates that the preceding expression for $G$ in terms of $p_{0}^{\prime}$ will probably overestimate the shear modulus if $p_{0}^{\prime}$ is substituted by $p_{0}$. The value of $G$ used in the present analysis of Maswoswe's results, $G=7 \mathrm{MPa}$, which provides a good fit for the experimental results, may be found if the expression for $G$ is computed for a value of $p_{0}{ }^{\prime}$ intermediate between $p_{0}(=0.2 \mathrm{MPa})$ and $p_{0}{ }^{*}(=0.02 \mathrm{MPa})$. It is also believed that secondary plastic strains take place within the elastic region bounded by the LC and SI yield loci and this will tend to underestimate the shear modulus which better fits the experimental results.

A summary of the model parameters discussed here and the initial stress conditions of the test analysed is given in Table 1 . Although the chosen parameters are consistent with the experimental evidence, it is recognized that other sets of parameter values might lead to similar model predictions.

The first part of the test represented in Figs 23 and 24 involves the application of vertical stress at constant water content. Suction was not controlled and its variation is a response of the sample to the boundary conditions. This type of test cannot be reproduced with the proposed model unless a relationship between water content (or, alternatively, degree of saturation $S_{\mathrm{r}}$ ) and the stress state $(p, q, s)$ is established. A simple way to model this relationship is to use the concept of state surface as described, for instance, in Lloret and Alonso (1985). In general $S_{\mathrm{r}}$ depends markedly on $s$ whereas the influence of applied stress is small (Alonso, Gens \& Hight, 1987). Accordingly, the following relationship

$$
S_{\mathrm{r}}=1-m \tanh (n s)
$$

where $m$ and $n$ are constants, has been used. Lloret and Alonso (1985) found that this expression fitted well published experimental results for soils with degrees of saturation over 0.4 . Maswoswe's results for test SK3 can be approximated with the values $n=5.38 \mathrm{MPa}^{-1}, m=0.64$. The loading process at constant water content could now be modelled in an iterative way by imposing that the $S_{\mathrm{r}}$ values derived from the computed deformations of the sample should match the values given by Equation (30).

Using the parameters and the initial and reference stress values indicated in Table 1 the computed model predictions, plotted in Fig. 24, show a satisfactory agreement with the measured results. The model correctly predicts that the $K_{0}$ value after collapse corresponds to $K_{0}$ for saturated specimens.

More than the success in predicting accurately a particular test in this case should be stressed the capability of the model to reproduce the basic features of a relatively complicated stress path such as the loading and collapse under $K_{0}$ conditions. 
Tests on partially saturated compacted kaolin reported by Karube (1986)

The results of several tests on partially saturated compacted kaolin in a triaxial cell were reported by Karube (1986). The following basic properties of the soil are provided in this reference: $w_{\mathrm{L}}=37 \% ; \mathrm{IP}=28 \%$; clay fraction: $22 \%$; maximum size of particles: $0.04 \mathrm{~mm}$. Among the different results reported, two tests corresponding to the stress paths shown in Fig. 25(a) have been selected for comparison with the model developed.

These two tests are particularly interesting since they reveal most of the patterns of behaviour of partially saturated soil, discussed in pre-

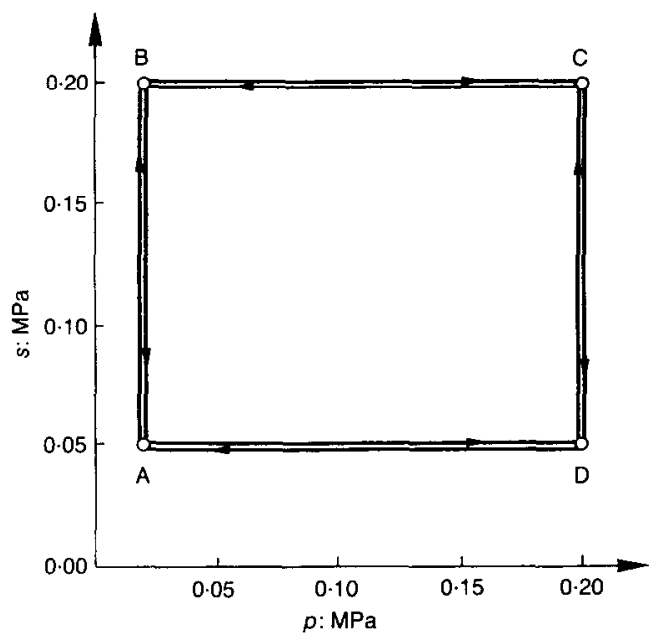

(a)

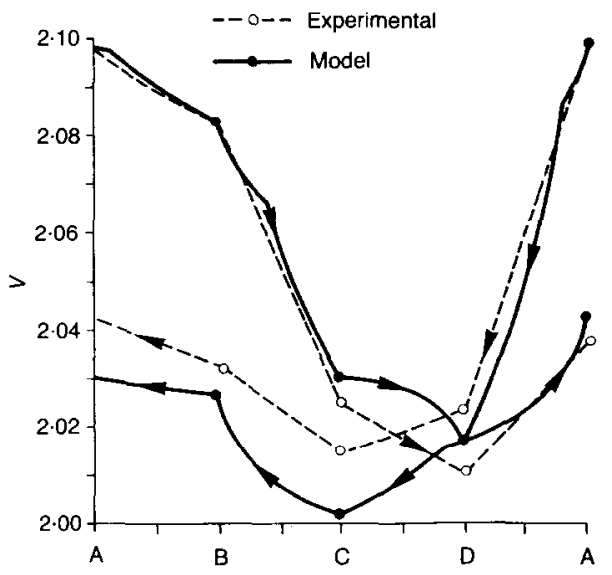

(b)

Fig. 25. Tests on compacted kaolin reported by Karube (1986): (a) stress paths; (b) comparison between experimental and computed results vious sections of this Paper. The samples used in the tests were compacted at a water content $6 \%$ dry of optimum and they had $S_{\mathrm{r}}=0.627$ and $v=2 \cdot 114$. They were subsequently consolidated under the initial stress state $(p=0.02 \mathrm{MPa}$; $s=0.05 \mathrm{MPa}$ ) and they reached $S_{\mathrm{r} 0}=0.645$ and $v_{0}=2.098$. Two alternative isotropic stress paths, shown in Fig. 25(a), starting and ending at the same stress point were followed by Karube (1986). The variation of specific volume is plotted in Fig. 25(b).

In order to derive the model parameters, the results reported by Karube have been used in the following way.

The value of $\kappa$ is directly related to the behaviour observed in the path steps C to B and D to $A$ which involve unloading of the net mean stress. The behaviour in the steps $B$ to $C$ and $A$ to $D$ is controlled by the parameters $\lambda(0), p^{c}, \beta, r$ and $p_{0}{ }^{*}$ as well as $\kappa$. Given the relatively low water content used in compaction, the soil should have a low compressibility. The values $\lambda(0)=0.065$ and $p^{\mathfrak{c}}=0.01 \mathrm{MPa}$ were first selected and the remaining parameters mentioned were subsequently determined from the measured results along the stress path steps indicated. It was estimated: $\kappa=0.011 ; \beta=20 \mathrm{MPa}^{-1} ; r=0.75$ and $p_{0}^{*}=0.04 \mathrm{MPa}$. The value of $\kappa_{\mathrm{s}}$ is directly related to the wetting path under low confining stress (B to $A$ ) and it was found $\kappa_{\mathrm{s}}=0.005$. In the drying paths $A$ to $B$ and $D$ to $C$ both $\lambda_{s}$ and $s_{0}$, as well as $\kappa_{\mathrm{s}}$, are relevant. Using the reported results it was found $\lambda_{\mathrm{s}}=0.025$ and $s_{0}=$ $0.07 \mathrm{MPa}$.

All of these parameters and the initial and reference stress states have been summarized in Table 1. Model predictions using these values are plotted in Fig. 25(b). The quantitative agreement is in this case satisfactory. Even more important is, again, the ability of the model to reproduce the main features of the measured behaviour.

\section{CONCLUDING REMARKS}

A review of the main characteristics of the behaviour of partially saturated soils has shown that existing models cover only limited aspects of the stress-strain response of these soils. Using as effective stress fields two independent stress variables-the excess of total stress over air pressure and the water pressure deficiency (or suction)-an elastoplastic hardening model has been developed and is described in the Paper. It accounts for the stiffness changes of the soil induced by suction changes, reproduces the irreversible response of the soil against stress and suction reversals, provides the conditions for collapsibility and links the amount of collapse to the 
stiffness changes of the soil induced by changes in suction. For isotropic stress conditions the model is characterized by two yield curves (LC; loading-collapse and SI, suction-increase) whose hardening laws are controlled by the total plastic volumetric deformation. These curves become yield surfaces when a third axis (accounting for shear stress) is introduced to model triaxial stress states. The behaviour of saturated soils is a particular case of the model developed which is reached when suction becomes zero. Different constitutive models for saturated conditions can be coupled to the unsaturated formulation presented in this Paper. For simplicity, a critical state model has been used as the reference model for saturated soil.

For applications that involve stress paths which imply monotonic wetting of the soil (which may be the case of embankment dam construction and subsequent water impounding) the model is characterized by nine constants, five more than the critical state model. These additional five constants account for phenomena typically associated with the behaviour of partially saturated soils such as decrease in stiffness and strength with suction decrease, collapse and (moderate) expansion of the soil when wetted. An additional parameter is required when the stress path implies suction increases beyond the maximum past suction value. Suitable testing procedures for obtaining the model parameters have been indicated.

As described in the Paper the model provides a simple representation of swelling, but is unable to approximate the behaviour of highly expansive soils. It is therefore intended for use with partially saturated soils of moderate to low plasticity, such as sandy clays, clayey sands and silts, and granular soils.

Extension and further elaboration of the proposed model may be envisaged to improve the descriplion of partially saturated soil behaviour. Some aspects not specifically included in the model are the irreversible nature of expansion in swelling clays, the decrease in collapse potential when the confining stress becomes larger than a critical or threshold value and the non-linear character of the strength envelope. It is believed, however, that before such extensions are made more experience should be gained with the model in its simplest forms.

The comparison made between the results of several suction controlled tests on low plasticity kaolin and a sandy clay and model predictions is encouraging. The examples analysed demonstrate that the model is capable of making accurate predictions. More significant perhaps is the possibility of reproducing relevant features of partially saturated soil behaviour in a unified context.

\section{ACKNOWLEDGEMENTS}

The authors express their gratitude for the support received from the CAICYT (Comision Asesora de Investigación Científica y Técnica) through research projects $2673 / 83$ and PB860379 .

\section{APPENDIX 1. MATHEMATICAL FORMULATION OF} CONSTITUTIVE MODEL

An ordered summary of the proposed model is presented here. The plastic strain increments can be obtained following standard procedures of the theory of hardening plasticity.

\section{Yield surfaces}

Two yield surfaces have been defined (in terms of the following stress variables: $p=\left(\sigma_{1}+2 \sigma_{3}\right) / 3-u_{\mathrm{a}} ; q=$ $\left.\sigma_{1}-\sigma_{3} ; s=u_{2}-u_{w}\right):$

$$
f_{1}\left(p, q, s, p_{0}^{*}\right) \equiv q^{2}-M^{2}\left(p+p_{s}\right)\left(p_{0}-p\right)=0
$$

where

$$
\begin{aligned}
& p_{s}=k s \\
& \frac{p_{0}}{p^{c}}=\left(\frac{p_{0}^{*}}{p^{c}}\right)^{[\lambda(0)-\kappa] /[\lambda(s)-\kappa]} \\
& \lambda(s)=\lambda(0)[(1-r) \exp (-\beta s)+r] \\
& f_{2}\left(s, s_{0}\right) \equiv s-s_{0}=0
\end{aligned}
$$

$p_{0}$ and $p_{0}{ }^{*}$ are preconsolidation $p$ stresses for suction $s$ and for saturated conditions respectively.

\section{Flow rules}

The plastic strain increment associated with yield surface $f_{1}$ is $\left(\mathrm{d} \varepsilon_{\mathrm{vp}}{ }^{\mathrm{p}}, \mathrm{d} \varepsilon_{\mathrm{s}}{ }^{\mathrm{p}}\right)$,

$$
\begin{aligned}
\mathrm{d} \varepsilon_{\mathrm{vp}}{ }^{\mathrm{p}} & =\mu_{1} n_{\mathrm{p}} \\
\mathrm{d} \varepsilon_{\mathrm{s}}{ }^{\mathrm{p}} & =\mu_{1} n_{\mathrm{q}}
\end{aligned}
$$

where

$$
\begin{aligned}
& n_{\mathrm{p}}=1 \\
& n_{\mathrm{q}}=\left[2 q \alpha / M^{2}\left(2 p+p_{\mathrm{s}}-p_{0}\right)\right]
\end{aligned}
$$

In Equation (39) $\alpha$ is a constant which can be derived by requiring that the direction of plastic strain increment for zero lateral deformation,

$$
\frac{\mathrm{d} \varepsilon_{\mathrm{s}}{ }^{\mathbf{p}}}{\mathrm{d} \varepsilon_{\mathrm{vp}}{ }^{\mathrm{p}}}=(2 / 3)\{1 /[1-\kappa / \lambda(0)]\}
$$

(where for simplicity $\mathrm{d} \varepsilon_{\mathrm{s}}{ }^{\mathrm{e}}$ has been assumed to be zero), is found for stress states satisfying $K_{0}$ conditions:

$$
\left(q / p+p_{\mathrm{s}}\right)=3\left(1-K_{0}\right) /\left(1+2 K_{0}\right)
$$

Equations (6), (39-41) provide

$$
\alpha=\frac{M(M-9)(M-3)}{9(6-M)}\{1 /[1-\kappa / \lambda(0)]\}
$$


For the yield surface $f_{2}$ the associated plastic strain vector is $\left(\mathrm{d} \varepsilon_{\mathrm{vs}}^{\mathrm{p}}, 0\right)$ where

$$
\mathrm{d} \varepsilon_{\mathrm{vs}}^{\mathrm{p}}=\mu_{2}
$$

Both $\mu_{1}$ and $\mu_{2}$ can be obtained through plastic consistency conditions.

\section{Hardening laws}

The evolution of the yield surfaces is controlled by the hardening parameters $p_{0}{ }^{*}$ and $s_{0}$. They depend on the total plastic volumetric strain increment $\mathrm{d}_{\mathrm{v}}{ }^{\mathrm{p}}$ as follows

$$
\begin{aligned}
& \frac{\mathrm{d} p_{0}{ }^{*}}{p_{0}{ }^{*}}=\frac{v}{\lambda(0)-\kappa} \mathrm{d} \varepsilon_{\mathrm{v}}{ }^{\mathrm{p}} \\
& \frac{\mathrm{d} s_{0}}{\left(s_{0}+p_{\mathrm{at}}\right)}=\frac{v}{\lambda_{\mathrm{s}}-\kappa_{\mathrm{s}}} \mathrm{d} \varepsilon_{\mathrm{v}}{ }^{\mathrm{p}}
\end{aligned}
$$

\section{Elastic strains}

The volumetric and shear elastic components of strain are given by

$$
\begin{aligned}
\mathrm{d} \varepsilon_{\mathrm{v}}{ }^{\mathrm{c}} & =\frac{\kappa}{v} \frac{\mathrm{d} p}{p}+\frac{\kappa_{\mathrm{s}}}{v} \frac{\mathrm{d} s}{\left(s+p_{\mathrm{at}}\right)} \\
\mathrm{d} \varepsilon_{\mathrm{s}}{ }^{\mathrm{e}} & =(1 / 3 G) \mathrm{d} q
\end{aligned}
$$

\section{REFERENCES}

Aitchison, G. D. \& Donald, I. B. (1956). Some preliminary studies of unsaturated soils. (b) Effective stresses in unsaturated soils. Proc. 2nd Austr.-N. Zealand Conf. Soil Mech. Fdn Engng, Christchurch, 192-199.

Alonso, E. E., Gens, A. \& Hight, D. W. (1987). Special problem soils. General report. Proc. 9th European Conf. Soil Mech. Fdn Engng, Dublin, 3, 1087-1146.

Barden, L., Madedor, A. O. \& Sides, G R. (1969). Volume change characteristics of unsaturated clays. J. Soil Mech. Fdn Engng, Am. Soc. Civ. Engrs 95, SM1, 33-51.

Bishop, A. W. \& Blight, G. E. (1963). Some aspects of effective stress in saturated and partly saturated soils. Géotechnique 13, No. 3, 177-197.

Bishop, A. W. \& Donald, I. B. (1961). The experimental study of partly saturated soils in the triaxial apparatus, Proc. 5th. Int. Conf. Soil Mech. Fdn Engng 1, 13-21.

Blight, G. E. (1965). A study of effective stress for volume change. In Moisture equilibria and moisture changes in soils beneath covered areas, pp. 259-269. Sydney: Butterworths.

Booth, A. R. (1975). The factors influencing collapse settlement in compacted soils. Proc. 6th Regional Conf. for Africa on Soil Mech. Fdn Engng, Durban, 1, pp. $57-63$.

Brand, D. (1981). Some thoughts on rain-induced slope failures. Proc. 10th Int. Conf. Soil Mech. Fdn Engng, Stockholm, 3, pp. 373-376.

Burland, J. B. (1965). Some aspects of the mechanical behaviour of partially saturated soils. In Moisture equilibria and moisture changes beneath covered areas, pp. 270-278. Sydney: Butterworths.

Coleman, J. D. (1962). Stress strain relations for partly saturated soil. Correspondence to Geotechnique 12, No. 4, 348-350.

Cox, D. W. (1978). Volume change of compacted clay fill. Clay fills, pp. 79-86, London: ICE.

Delage, P., Suraj de Silva, G. P. R. \& De Laure, E. (1987). Un nouvel appareil triaxial pour les sols nonsaturés. Proc. 9th European Conf. Soil Mech. Fdn Engng, Dublin, 1, pp. 25-28.

Dudley, J. H. (1970). Review of collapsing soils. J. Soil Mech. Fdn Engng, Am. Soc. Civ. Engrs 96, SM3, 925-947.

Erol, O. A. \& El-Ruwaih, I. A. (1982). Collapse behaviour of desert loess. Proc. 4th Cong. IAEG 1, 443448.

Escario, V. \& Sáez, J. (1973). Measurement of the properties of swelling and collapsing soils under controlled suction. Proc. 3rd Int. Conf. Expansive Soils, Haifa, 196-200.

Escario, V. \& Sáez, J. (1986). The shear strength of partly saturated soils. Géotechnique 36 , No. 13, 453456.

Escario, V. \& Sáez, J. (1987). Shear strength of soils under high suction values. Written discussion. Session 5. Proc. 9th European Conf. Soil Mech. Fdn Engng, Dublin, 3, 1157.

Fredlund, D. G. (1979). Appropriate concepts and technology for unsaturated soils. Can. Geotech. J. 16, 121-139.

Fredlund, D. G. \& Morgenstern, N. R. (1977). Stress state variables for unsaturated soils. $J$. Gentech. Engng Div., Am. Soc. Civ. Engrs 103, GT5, 447-446.

Fredlund, D. G., Morgenstern, N. R. \& Widger, R. S. (1978). The shear strength of unsaturated soils. Can. Geotech. J. 15, No. 3, 313-321.

Fredlund, D. G. \& Rahardjo, H. (1985). Theoretical context for understanding unsaturated residual soil behaviour. Proc. Ist Int. Conf. on Geomech. in Tropical, Lateritic and Saprolitic Soils, Brasilia, 1, 295306.

Fredlund, D. G., Rahardjo, H. \& Gan, J. K. M. (1987). Nonlinearity of strength envelope for unsaturated soils. Proc. 6th Int. Conf. Expansive Soils, New Delhi, 49-54.

Gens, A. (1982). Stress-strain and strength characteristics of a low plasticity clay. PhD thesis, London University.

Gens, A. \& Potts, D. M. (1982a). A theoretical model for describing the behaviour of soils not obeying Rendulic's principle. Proc. 1st Int. Symp. Numer. Mod. Geomech., Zurich, 24-32.

Gens, A. \& Potts, D. M. (1982b). Application of critical state soil models to the prediction of the behaviour of a normally consolidated low plasticity clay. Proc. 1st Int. Symp. Numer. Mod. Geomech., Zurich, 312323.

Gens, A. \& Potts, D. M. (1988). Critical state models in computational geomechanics. Engineering Computations 8, No. 3, 178-197.

Gulhati, S. K. \& Satija, B. S. (1981). Shear strength of partially saturated soils, Proc. 10th Int. Conf. Soil Mech. Fdn Engng, Stockholm, 1, 609-612.

Ho, D. Y. F. \& Fredlund, D. G. (1982). Increase in 
strength due to suction for two Hong Kong soils. Proc. Conf. Engng and Construction in Tropical and Residual Soils, Honolulu, 263-295.

Jaky, J. (1948). Pressure in silos. Proc. 2nd Int. Conf. Soil Mech. and Fdn Engng 1, 103-107.

Jennings, J. E. \& Burland, J. B. (1962). Limitations to the use of effective stresses in partly saturated soils. Géotechnique 12, No. 2, 125-144.

Jennings, J. E. \& Knight, K. (1975). A guide to construction on with materials exhibiting additional settlement due to 'collapse' of grain structure. Proc. 6th Regional Conf. for Africa on Soil Mech. Fdn Engng, Durban, 1, 99-105.

Josa, A. (1988). Un modelo eslastoplástico para suelos no saturados. Tesis Doctoral. Universitat Politècnica de Catalunya, Barcelona.

Josa, A., Alonso, E. E., Lloret, A. \& Gens, A. (1987). Stress-strain behaviour of partially saturated soils. Proc. 9th European Conf. Soil Mech. Faln Engng, Dublin, 2, 561-564.

Justo, J. L., Delgado, A. \& Ruiz, J. (1984). The influence of stress-path in the collapse-swelling of soils at the laboratory. Proc. 5th Int. Conf. Expansive Soils, Adelaide, 67-71.

Karube, D. (1986). New concept of effective stress in unsaturated soil and its proving tests. ASTM Symp. on Advanced Triaxial Testing of Soil and Rock, ST 977, 539-552.
Lloret, A. \& Alonso, E. E. (1980). Consolidation of unsaturated soil including swelling and collapse behaviour. Geotechnique 30, No. 4, 449-477.

Lloret, A. \& Alonso, E. E. (1985). State surfaces for partially saturated soils. Proc. 11th Int. Conf. Soil Mech. Fdn Engng, San Francisco, 2, 557-562.

Maswoswe, J. (1985). Stress path for a compacted soil during collapse due to wetting. $\mathrm{PhD}$ thesis, Imperial College, London.

Matyas, E. L. \& Radhakrishna, H. S. (1968). Volume change characteristics of partially saturated soils. Géotechnique 18, No. 4, 432-448.

Ohmaki, S. (1982). Stress-strain behaviour of anisotropically, normally consolidated cohesive soil. Proc. lst Int. Symp. Num. Mod. Geomech., Zurich, 250269.

Rico, A. \& Del Castillo, H. (1976). La ingenieria de suelos en las vías terrestres. 1, Limusa, México.

Yong, R. N., Japp, R. D. \& How, G. (1971). Shcar strength of partially saturated clays. Proc. 4th Asian Reg. Conf. Soil Mech. Fdn Engng, Bangkok, 2, 12: 183-187.

Yudhbir, (1982). Collapsing behaviour of residual soils. Proc. 7th Southeast Asian Geotech. Conf., HongKong, 1, 915-930. 